IZA DP No. 5149

Estimating the Effect of the One-Child Policy on Sex Ratio Imbalance in China: Identification Based on the Difference-in-Differences

Hongbin Li

Junjian Yi

Junsen Zhang

August 2010 


\section{Estimating the Effect of the One-Child Policy on Sex Ratio Imbalance in China: Identification Based on the Difference-in-Differences}

Hongbin Li

Tsinghua University

and IZA

Junjian Yi

Chinese University of Hong Kong

Junsen Zhang

Chinese University of Hong Kong

and IZA

Discussion Paper No. 5149

August 2010

IZA

P.O. Box 7240

53072 Bonn

Germany

Phone: $+49-228-3894-0$

Fax: +49-228-3894-180

E-mail: iza@iza.org

Any opinions expressed here are those of the author(s) and not those of IZA. Research published in this series may include views on policy, but the institute itself takes no institutional policy positions.

The Institute for the Study of Labor (IZA) in Bonn is a local and virtual international research center and a place of communication between science, politics and business. IZA is an independent nonprofit organization supported by Deutsche Post Foundation. The center is associated with the University of Bonn and offers a stimulating research environment through its international network, workshops and conferences, data service, project support, research visits and doctoral program. IZA engages in (i) original and internationally competitive research in all fields of labor economics, (ii) development of policy concepts, and (iii) dissemination of research results and concepts to the interested public.

IZA Discussion Papers often represent preliminary work and are circulated to encourage discussion. Citation of such a paper should account for its provisional character. A revised version may be available directly from the author. 
IZA Discussion Paper No. 5149

August 2010

\section{ABSTRACT \\ Estimating the Effect of the One-Child Policy on Sex Ratio Imbalance in China: Identification Based on the Difference-in-Differences ${ }^{\star}$}

In China, the male-biased sex ratio has increased significantly. Because the one-child policy only applied to the Han Chinese but not to minorities, this unique affirmative policy allows us to identify the causal effect of the one-child policy on the increase in sex ratios by a difference-in-differences (DD) estimator. Using the 1990 census, we find that the strict enforcement of the one-child policy has led to 4.4 extra boys per 100 girls in the 1980s, accounting for about $94 \%$ of the total increase in sex ratios during this period. The robust tests indicate that the estimated policy effect is not likely confounded by other omitted policy shocks or socioeconomic changes. Moreover, we conduct the DD estimation using both the 2000 census and the 2005 mini-census. Our estimates suggest that the one-child policy has resulted in about 7.0 extra boys per 100 girls for the 1991-2005 birth cohort. The effect of the one-child policy accounts for about $57 \%$ and $54 \%$ of the total increases in sex ratios for the 1990s and the 2001-2005 birth cohorts, respectively.

JEL Classification: J13, J15, J18, O10

Keywords: one-child policy, sex ratio imbalance, difference-in-differences estimator

Corresponding author:

Junsen Zhang

Department of Economics

Chinese University of Hong Kong

Shatin, NT

Hong Kong

E-mail: jszhang@cuhk.edu.hk

\footnotetext{
* The work described in this paper was substantially supported by a grant from the Research Grants Council of the Hong Kong Special Administrative Region, China (Project no. CUHK 454608).
} 


\section{Introduction}

According to three recent waves of population censuses in China, the sex ratio at birth has drastically increased from 108.5 in 1982 , to 113.8 in 1990 , and to 119.9 in 2000 , deviating far from the biologically stable range from 103 to 107 (NBS, 2002) 1 Considering the farreaching consequences of the persisting sex ratio imbalance on both the marriage market and the labor market (Angrist, 2002; Becker, 1991; Chiappori, Fortin \& Lacroix, 2002; Rao, 1993), and even on the crime market (Dreze \& Khera, 2000; Edlund et al., 2008; Hudson \& Boer, 2002) 2 the problem of the male-biased sex ratio in China has drawn increasing attention from demographers, economists, and other social scientists (e.g., Banister, 2004; Coale \& Banister, 1994; Hesketh \& Xing, 2006; Qian, 2008; Tuljapurkar, Li \& Feldman, 1995; Zeng et al., 1993) 3 $^{3}$

However, the cause for the increase in sex ratio has been a subject of heated debate. Oster (2005) raises the possibility that a biological factor, hepatitis B, accounts for about $70 \%$ of the "missing women" in China. The hepatitis B story is questioned by Das Gupta (2005). Lin \& Luoh (2008) show direct micro evidence that hepatitis B does not affect the sex ratio in Taiwan. Oster and Chen (2008) also admit that hepatitis B does not explain male-biased sex ratios in China. Although the biological factor of hepatitis B seems to have been excluded from this "missing women" story originally discovered by Sen (1990), the debate has not totally resolved. Many economists and demographers argue that the one-child policy has been the major reason for the increase in sex ratios in China (Ebenstein, 2009; Li, 2002; Das Gupta, 2005; Zeng et al., 1993). Guilmoto (2009) discusses that the increase in sex ratios in Asia may be triggered by the progress in gender selection technology. Qian (2008) claims that a substantial percentage of the increase in sex ratio is attributable to the gender wage

\footnotetext{
${ }^{1}$ The sex ratio is defined as the number of males per 100 females in the reference population.

${ }^{2}$ It has also been suggested that the endogenized sex ratio by the son preference may systematically degenerate girls to be born in low status families (Edlund, 1999).

${ }^{3}$ Porter $(2007,2008)$ has analyzed the effects of the male biased sex ratio on marriage, intrahousehold bargaining, and intergenerational transfers; Wei \& Zhang (2008) have explored the effect of sex ratio imbalance on saving behavior in China.
} 
gap.

This paper argues that the increase in sex ratios in China has been a result of a combination of son preference, a decrease in fertility induced by the one-child policy, and the progress of gender selection technology. These elements are the three indispensable ingredients in the increase in sex ratios in China. Son preference is a cultural background; gender selection, such as gender-selective abortion, is a necessary tool through which a desired gender can be pursued; and the decrease in fertility induced by the one-child policy leads to increasing sex ratios. Given son preference and gender selection technology, the frequency or intensity of gender selection usage is different at different fertility levels. The increase in sex ratios is a manifestation of the decline in fertility caused by the one-child policy. With lower fertility coupled with gender selection to realize the desired gender, the impact of any factor on the sex ratio is higher. ${ }^{4}$

Previous research has tried to identify the causal relationship between the one-child policy and the increase in sex ratio by exploiting spatial and time variations in the implementation of the one-child policy. For example, Ebenstein (2009) utilizes the regional and temporal variation in fines at provincial level for unauthorized births, and finds that higher fine regimes are associated with higher sex ratios but lower fertility. The spatial and time variations of the one-child policy, however, may be endogenous to gender selection and sex ratios in empirical analysis: $5^{5}$

Our paper avoids this problem by designing a difference-in-differences estimator based on an exogenous differential treatment between the Han and minorities under the one-child policy. In the quasi-experiment design of the DD estimator, both the ethnic-specific het-

\footnotetext{
${ }^{4}$ The interaction between sex preference, fertility, and sex ratio has long been noticed in the literature (Becker, 1991; Ben-Porath \& Welch, 1976). Ben-Porath \& Welch (1976) conjecture a possibility that parents indirectly choose fertility to satisfy their sex preference. To test this hypothesis, however, there exists an identification problem because the number and gender composition of children are simultaneously determined. The Chinese experience may shed light on this problem because the fertility behavior there had been exogenously targeted by the one-child policy since 1979. Therefore, identifying the effect of the one-child policy on sex ratio imbalance in China can help our understanding of the interaction between fertility and sex ratios in countries where son preference is prevalent.

${ }^{5}$ It will be discussed in detail in Subsection 2.2.
} 
erogeneity and the effects of socioeconomic development have been swept out. Therefore, the DD estimate is very clean, and we are able to rigorously identify the causal effect and obtained the quantitative effect of the one-child policy on sex ratio imbalance in China.

The one-child policy stipulates that each couple is allowed only one-child. Couples are given birth quotas, and they are penalized for "above-quota" births. However, a unique feature of the one-child policy is that minority women were generally allowed to have at least two children whereas the Han can only have one child $!^{6}$ The differential treatment of the onechild policy across different ethnic groups has been embodied in various regulations (Banister, 2004; Hardee-Cleaveland \& Banister, 1988; Park \& Han, 1990; Scharping, 2003). In addition, the motivation of the differential treatment of the one-child policy across ethnic groups has been evidently exogeously imposed. Therefore, the consistently differential treatment of the one-child policy between the Han and other minorities provides us a precious and unique opportunity to identify its causal effect on the sex ratio imbalance in China..$^{7}$

Using the Chinese population census in 1990, the estimated treatment effect on the probability of being a boy is as large as 1.01 percentage points for the 1980s birth cohort. This means that the strict enforcement of the one-child policy has causally increased the sex ratio by 4.4 which accounts for about $94 \%$ of the increase in sex ratios during this period. Our robust analysis indicates that the estimated treatment effect is unlikely confounded by other omitted policy shocks or socioeconomic changes. We further conduct the DD estimation using both the 2000 census and 2005 mini-census. Our DD estimates suggest the one-child policy has increased the sex ratio by about 7.0 for birth cohort of 1991-2005. The policy

\footnotetext{
${ }^{6}$ Second birth was strictly forbidden at the early stage of the implementation of the one-child policy after 1979. However, Central Document 7 issued in early 1984 by the Party Central Committee allows rural couples to have a second child if the first was a girl (Peng, 1996).

${ }^{7}$ Two facts greatly substantiate the validity of our quasi-experiment design of the DD estimator. First, there is clear evidence that the sex ratios for minorities and the Han were very close prior to the enactment of the one-child policy but diverged significantly afterwards. Second, there is little difference in changes of family structure, mother's age at the first birth, parental characteristics, and parental labor market behaviors between the Han and minorities during the post-treatment period. Li \& Zhang (2009) construct a similar DD estimator based on the differential treatment across ethnical groups to test the external effects of fertility behavior. Li \& Zhang (2007) also exploit the differential ethical treatment to construct an instrumental variable to identify the effect of (endogenous) population growth on economic growth.
} 
effect accounts for about $57 \%$ and $54 \%$ of the increase in sex ratios for the birth cohorts in the 1990s and 2001-2005, respectively.

The rest of the paper is organized as follows. Section 2 describes the background. Section 3 specifies the empirical strategy and introduces the data set. Section 4 reports the empirical results. Section 5 analyzes the effects of the one-child policy by birth order. Section 6 estimates the effects of one-child policy by registration type. Section 7 conducts our robust analysis. Section 8 carries out the DD estimation using the 2000 census and 2005 mini-census. Section 9 concludes.

\section{Background}

\subsection{The increase in Sex Ratio in China}

Although scattered historical statistics indicate that China has had a traditionally malebiased sex ratio, the sex ratio at birth was relatively stable and was only marginally higher than western countries from the foundation of the People's Republic of China in 1949 to the beginning of the one-child policy in 1979, except the birth cohorts of 1956-1958 who were born just prior to the Great Famine. Based on four modern waves of the Chinese population census after 1949 and two large-scale in-depth fertility surveys, Coale \& Banister (1994) systematically document sex ratios for the birth cohorts from 1936-1989, and convincingly demonstrate that the reported sex ratio at birth was very close to 106-107 throughout the 1960s and 1970s. $\square^{8}$ Figure 1 depicts the time series of sex ratios by birth cohort from 1949 to 1990 projected by the Chinese population census in 19909 It confirms that the sex ratio in pre-policy change period before 1979 is significantly lower than that in the post-policy change period. In fact, the mean value of the sex ratio for the birth cohorts from 1949 to 1978 is 106.6. Figure 1 also shows that the sex ratio almost experiences a monotonic increase after 1979, and attains an unprecedented level of 113.8 in 1990.

\footnotetext{
${ }^{8}$ The four modern population censuses used in Coale \& Banister (1994) were held in 1953, 1964, 1982, and 1990, respectively; and the two in-depth fertility surveys were carried out in 1982 and 1988, respectively.

${ }^{9}$ This figure is very similar to Figure 2 in Coale \& Banister (1994, p.466) except that their cohort analysis is conducted in a five-year moving average form to smooth out irregular disturbances.
} 
It has been claimed that a substantial percentage of the increase in sex ratio is due to the gender wage gap (Qian, 2008). Although the correlation between the relative female income to the total household income and the outcomes for boys and girls, including female survival rates, has been extensively investigated in the literature (Duflo, 2003; Foster \& Rosenzweig, 1999; Rosenzweig \& Schultz, 1982; Thomas, 1994), the magnitude of the time series change of gender-specific earning gap does not match the magnitude of the increase in sex ratios in China during the past three decades (Cai, Park, \& Zhao, 2008; Rozelle et al., 2002). Based on an empirical analysis on gender earning gap in China's rural areas, Rozelle et al. (2002) conclude "no evidence was found to suggest that the economic reform policies and market competition had led to any measurable increase or decrease in gender wage discrimination". Similarly, Figure A1 in the Appendix cites the statistics in Zhang et al. (2008) showing that the gender earning gap has been rather stable during the past two decades in urban China, though it has experienced a marginal increase $t^{10}$ Thus, the gender-specific earning gap could account for only a small portion of the increase in sex ratios in China.

We believe that the increase in sex ratio has been a result of a combination of son preference, the progress of gender selection technology, and low fertility rates regulated by the one-child policy. First, son preference is a cultural background. There is no doubt that the male-biased sex ratio in China is associated with son preference which is traditionally rooted in Chinese society. However, the traditional son preference alone cannot explain the recent increase in sex ratios because as a preference it is relatively stable. Second, gender selection such as gender-selective abortion is a necessary tool. Without the progress in gender selection technology, gender selection such as selective abortion would be infeasible, and thus the sex ratio would not be unbalanced $[11$ Furthermore, regardless of which factors are the ultimate causes of the high sex ratio, they all have to involve gender selection technology

\footnotetext{
${ }^{10}$ Descriptive statistics from various sources show that the ratio of female wages to male wages has hovered around $80 \%$ throughout the 1980s and 1990s, which is comparable to its counterparts in the US during the same period (Blau \& Kahn, 1997; Gustafsson \& Li, 2000; Meng, 1998).

${ }^{11}$ For example, during the 1970s, the total fertility rate dropped from near 6 to 2.3 under the later-longerfewer policy. However, there was not much change in sex ratios during this period. The absence of gender selective induced abortion seems a plausible explanation.
} 
and induced abortion. However, gender selection technology alone cannot bias the sex ratio too much when fertility is high.

Finally, the decrease in fertility induced by the one-child policy can itself lead to the rise in sex ratio for given son preference and gender selection technology. Assuming that "at least one boy" is the preferred gender composition of children, parents can achieve their target by manipulating fertility without resorting to gender selection technologies. For example, if the total fertility rate is higher than 5 as in the pre-policy change period from 1949 to 1979, the probability of failing the preferred gender composition target is less than $2.5 \%$. On the contrary, a substantial percentage of parents are more likely to practice gender selection when fertility is compressed to 1 or 2 by the one-child policy, and the probability of failing to have "at least one boy" increases to $50 \%$ or $25 \%$.

Given that both the Han Chinese and minority groups have exposure to a similar change in gender selection technology, the difference in the change of sex ratios between the Han Chinese and the minority group is thus ascribed to the difference in the change of fertility induced by the different one-child policy treatment. In addition, the sex ratios between the Han and minorities were very close before the one-child policy. Therefore, our DD estimate identifies the causal effect of the one-child policy on sex ratio conditional on son preference and gender selection technology.

\subsection{The One-Child Policy in China}

After the termination of the Cultural Revolution in 1976, the Chinese leadership was shocked by the fact that while the grain production in 1977 stagnated at the level of 1955, the overall population had almost doubled from 614 million in 1955 to 949 million in $1977 .{ }^{12}$ Thus, the fear of a Malthusian catastrophe compelled the Communist leaders to take a radical birth planning policy, the one-child policy, which began in the late 1970s. It is possibly the largest

\footnotetext{
${ }^{12}$ The cultivated area per capita shrank from 0.22 hectares in 1949 to 0.08 in 1977 , far below the world standard, in which about half of the acreage consisted of low-yield areas (Scharping, 2003).
} 
social experiment in human history ${ }^{13}$ After its promulgation, however, the implementation of the one-child policy has exhibited three distinctive features which may have brought problems to the estimation of its demographic, social and economic effects.

First, instruments employed in the implementation of the one-child policy have exhibited great diversifications. They range from the mild methods of economic incentives and fines, propaganda and educational work, effective diffusion of contraceptives, and commitment and subscription of the One-Child Certification, to extreme sanctions such as mandatory IUD insertions, the refusal of water and electricity supplies, the unroofing of peasant families' homes for violation, enforced abortion for above quota pregnancies, etc. (Scharping, 2003). In practice, rather than a single policy, the one-child policy appears to be a set of policies. The fine for above quota birth is just one piece in the set of instruments. Moreover, the adoptions and emphases of these policy instruments have varied from year to year, and from region to region.

Second, there has been different rigidity or flexibility in implementing the one-child policy across different regions and different years. Although the enforced one-child policy began as early as in the late 1970s, the official Population and Family Planning Law was enacted as late as 2002. The implementation of the one-child policy had been through various executive regulations and rules. Thus, both the central and local governments are given substantial discretionary power to adjust the policy strictness in response to demographic, social, and economic changes. For example, the release of the Central Document 7 in 1984 eased the strictness of the one-child policy to a certain extent, and explicitly specified exceptional conditions under which two children were allowed. Based on local conditions, families in certain areas were allowed to have a second child if the first one was a girl after the release of the Document. However, the central government late noted the laxity and a "loss of control" in the Document, and called for strict adherence to population targets. Finally, it was replaced by Central Document 13 issued in 1986, which is more stringent than the

\footnotetext{
13 "The commitment to birth planning is the duty of citizens and the task of lower level administrations" is even officially prescribed in the Chinese Constitution Law (article 49).
} 
previous stipulation (Peng, 1996; Scharping, 2003).

Finally and most importantly, the spatial and time variations may be endogenous to sex ratios. These variations may reflect the unobserved interaction between regional heterogeneities (e.g., son preference and socioeconomic development). The unobserved interaction can also affect gender selection and sex ratios. Based on panel data from the China Health and Nutrition Survey, Short and Zhai (1998) suggest that variations in the enforcement strictness of the one-child policy have been based on local demographic, social, and economic conditions. Li and Zhang (2008) find that the level of the fine increases with the community wealth level and the local government's birth control incentives, but decreases with the local government's revenue incentives. In particular, the spatial and time variations in the one-child policy have been documented as being affected by the fertility rate. As discussed above, the central government explicitly tightened up the one-child policy in 1986 in response to the high fertility resulted by the Central Document 7 in 1984. Since fertility affects both sex ratio and government policy, every factor that affects fertility would likely affect sex ratio and the strictness of the one-child policy simultaneously 14

In summary, the instrument-, time-, and region-varying natures of its implementation listed above make the measurement and the identification of the causal effect of the one-child policy on sex ratio imbalance extremely difficult, especially at the national level. However, there is a general rule with the one-child policy that minority women were normally allowed to have at least two children until the end of the 1980s, which is clear-cut and uniform across regions and years. The differential treatment across ethnic groups has been embodied in all documents of birth planning policies, and has even been officially written into the Law on Regional National Autonomy (Peng, 1996). Therefore, the differential treatment of the one-child policy between the Han and other minorities serves as a precious and unique

\footnotetext{
${ }^{14}$ After the rural household responsibility system reform in the early 1980 s, the central government actually lost the ability to directly control peasant income, land use, and collective welfare funds. Hence, a uniform prescription of economic incentives or sanctions, and other implementing methods at the national level were not exercisable for the central government. The central government only set the general rule for the onechild policy, while its interpretation, adoption, and implementation were based on local conditions and needs (Peng, 1996).
} 
quasi-experiment to identify the causality between the one-child policy and the increase in sex ratios in China.

\section{Empirical Strategy and Data Description}

\subsection{Empirical Strategy}

This paper is interested in estimating the effect of the one-child policy on sex ratios. However, sex ratios cannot be defined at the individual level. Therefore, we will first estimate the policy effect on the probability of being a boy at the individual level. We then translate it into the policy effect on sex ratios at the population level by a nonlinear transformation. As discussed in previous sections, the differential treatment of the one-child policy between the Han and other minorities serves as a quasi-experiment to identify the causal effect on the sex ratio imbalance. Since the one-child policy has only been applied to the Han, we have the Han Chinese as the treatment group and the ethnic minorities as the comparison group. Let $S_{i}$ be a child's gender status; $S_{i}=1$ if the child is a boy, otherwise 0 . In addition, let $H$ and $T$ be the ethnic and birth cohort indicators, respectively; $H$ equals 1 for a Han child, and $T$ equals 1 if the child was born in the post-policy change period (after 1979). ${ }^{15}$ Therefore, we have four groups: Han Chinese born before 1979, Han Chinese born after 1979, minorities born before 1979, and minorities born after 1979. The average probabilities of being a boy for the four groups can be denoted as

\begin{tabular}{|l|l|l|}
\hline & Han & Minority \\
\hline Born before 1979 & $E\left(S_{i} \mid H=1, T=0\right)$ & $E\left(S_{i} \mid H=0, T=0\right)$ \\
\hline Born after 1979 & $E\left(S_{i} \mid H=1, T=1\right)$ & $E\left(S_{i} \mid H=0, T=1\right)$ \\
\hline
\end{tabular}

\footnotetext{
${ }^{15}$ Before the implementation of the one-child policy in 1979, the Chinese government had initiated a voluntary "late, long, few" policy which called for later childbearing, greater spacing between children (normally four years), and fewer children since 1972. Thus, the one-child policy may impose an unexpected constraint even for birth cohorts 1976-1978. However, parent who had given birth to a girl in, say, 1977, could not anticipate the enforcement of the one-child policy in 1979. Thus, they had no incentive to practice gender selection and thought they could give birth to another child four years later. In this case, it is the expected fertility rather than actual fertility that has affected parent's gender selection behavior. Therefore, it is appropriate to treat the birth cohort before 1980 as the pre-policy change group in estimating the effect of the one-child policy on sex ratio imbalance.
} 
We use the following DD framework to control for systematic differences across both ethnic groups and birth cohorts. Differencing the mean value of $S_{i}$ across birth cohorts and ethnic groups gives

$$
\begin{aligned}
D D= & {\left[E\left(S_{i} \mid H=1, T=1\right)-E\left(S_{i} \mid H=1, T=0\right)\right]-} \\
& {\left[E\left(S_{i} \mid H=0, T=1\right)-E\left(S_{i} \mid H=0, T=1\right)\right] }
\end{aligned}
$$

In the equation above, our estimated DD captures the causal effect of the one-child policy on the sex ratio imbalance. Specifically, the time-invariant and ethnic-specific factors are cleared out in the two differences of $E\left(S_{i} \mid H=1, T=1\right)-E\left(S_{i} \mid H=1, T=0\right)$ and $E\left(S_{i} \mid H=0, T=1\right)-E\left(S_{i} \mid H=0, T=1\right)$, respectively. Then in the second step, any changes not due to the intervention of the one-child policy, while common to both the Han and other minorities are eliminated in the difference of $\Delta E\left(S_{i} \mid H=1\right)-\Delta E\left(S_{i} \mid H=0\right)$. In other words, our DD estimate has netting out the effect of socioeconomic development, and it only reflects the effect of the one-child policy.

In practice, the following regression-adjusted DD model is used to identify the effect of the one-child policy on the probability of being a boy

$$
S_{i}=\alpha_{0}+\alpha_{1} H_{i}+\alpha_{2} T_{i}+\alpha_{3}\left(H_{i} * T_{i}\right)+\varepsilon_{i}
$$

where the two dummy variables, $H_{i}$ and $T_{i}$, pick up the ethnic and time effects, respectively. For example, the effect of socioeconomic development on the probability of being a boy is reflected by $\alpha_{2}$. The coefficient of our interest is on the interactive term of $H_{i} * T_{i}$, which captures the causal effect of the one-child policy on the gender of a Han child who was born after 1979. In fact, $\alpha_{3}$ is identical to our DD in Equation (1). To see it clearly, we plug the dummy variables into Equation (2) above, and then the average probabilities of being a boy for the four groups are 


\begin{tabular}{|l|l|l|l|}
\hline & Han & Minority & Difference \\
\hline Before 1979 & $\alpha_{0}+\alpha_{1}$ & $\alpha_{0}$ & $\alpha_{1}$ \\
\hline After 1979 & $\alpha_{0}+\alpha_{1}+\alpha_{2}+\alpha_{3}$ & $\alpha_{0}+\alpha_{2}$ & $\alpha_{1}+\alpha_{3}$ \\
\hline Difference & $\alpha_{2}+\alpha_{3}$ & $\alpha_{2}$ & $\alpha_{3}$ \\
\hline
\end{tabular}

Thus, the policy effect on the probability of being a boy is $\left[\left(\alpha_{0}+\alpha_{1}+\alpha_{2}+\alpha_{3}\right)-\left(\alpha_{0}+\alpha_{1}\right)\right]-$ $\left[\left(\alpha_{0}+\alpha_{2}\right)-\alpha_{0}\right]=\alpha_{3}$

Using the estimates in Equation (2), we are able to derive the policy effect on sex ratios. Specifically, the ratio of males over females for the four groups are as follows,

\begin{tabular}{|l|l|l|}
\hline & Han & Minority \\
\hline Before 1979 & $\left(\alpha_{0}+\alpha_{1}\right) /\left[1-\left(\alpha_{0}+\alpha_{1}\right)\right]$ & $\alpha_{0} /\left(1-\alpha_{0}\right)$ \\
\hline After 1979 & $\left(\alpha_{0}+\alpha_{1}+\alpha_{2}+\alpha_{3}\right) /\left[1-\left(\alpha_{0}+\alpha_{1}+\alpha_{2}+\alpha_{3}\right)\right]$ & $\left(\alpha_{0}+\alpha_{2}\right) /\left[1-\left(\alpha_{0}+\alpha_{2}\right)\right]$ \\
\hline
\end{tabular}

Thus, the policy effect on sex ratio $(P E S R)$ can be calculated as

$$
\begin{aligned}
\operatorname{PESR}= & 100 *\left\{\left\{\left(\alpha_{0}+\alpha_{1}+\alpha_{2}+\alpha_{3}\right) /\left[1-\left(\alpha_{0}+\alpha_{1}+\alpha_{2}+\alpha_{3}\right)\right]-\left(\alpha_{0}+\alpha_{1}\right) /\left[1-\left(\alpha_{0}+\alpha_{1}\right)\right]\right\}\right. \\
& \left.-\left\{\left(\alpha_{0}+\alpha_{2}\right) /\left[1-\left(\alpha_{0}+\alpha_{2}\right)\right]-\alpha_{0} /\left(1-\alpha_{0}\right)\right\}\right\}
\end{aligned}
$$

We multiply 100 on the right hand side of Equation (3) above because that the sex ratio is defined as the number of males per 100 females in the population. Furthermore, we are able to statistically test the policy effect on sex ratios by using the estimates in Equation (2) with the null hypothesis $P E S R=0$. It can be test by using a Wald-type non-linear test, which is based on the delta method. Finally, we can figure out the percentage of the increase in sex ratios which is due to the one-child policy $(P O C P)$ for the Han Chinese as

$$
P O C P=P E S R /\left\{\left(\alpha_{0}+\alpha_{1}+\alpha_{2}+\alpha_{3}\right) /\left[1-\left(\alpha_{0}+\alpha_{1}+\alpha_{2}+\alpha_{3}\right)\right]-\left(\alpha_{0}+\alpha_{1}\right) /\left[1-\left(\alpha_{0}+\alpha_{1}\right)\right]\right\},
$$

where $\left\{\left(\alpha_{0}+\alpha_{1}+\alpha_{2}+\alpha_{3}\right) /\left[1-\left(\alpha_{0}+\alpha_{1}+\alpha_{2}+\alpha_{3}\right)\right]-\left(\alpha_{0}+\alpha_{1}\right) /\left[1-\left(\alpha_{0}+\alpha_{1}\right)\right]\right\}$ is the total increase in sex ratios for the Han Chinese, and PESR is the part attributed to the one-child 
policy.

Using the regression framework, we are able to control for other demographic, geographic, and socioeconomic characteristics,

$$
S_{i}=\alpha_{0}+\alpha_{1} H_{i}+\alpha_{2} T_{i}+\alpha_{3}\left(H_{i} * T_{i}\right)+X_{i}^{\prime} \beta+\varepsilon_{i}
$$

where $X_{i}$ is a vector of control variables ${ }^{16}$ Our empirical results experience very mild change when we include $X_{i}$ as shown in the next section.

The key identifying assumption of the DD estimator is that the coefficient on the interaction term of $H_{i} * T_{i}$ in Equation (2) should be zero in the absence of the one-child policy (Angrist \& Krueger, 1999). In other words, minorities should be a suitable comparison group for the Han in identifying the treatment effect of the one-child policy on sex ratio imbalance in China (Meyer, 1995). The validity of our DD estimator will be extensively discussed here and will be systematically tested in next sections.

First, the possibility of an endogenously differential treatment of the one-child policy between the Han and other minorities can be safely excluded 17 From the early documents on the motivation of the one-child policy, the decision of the non-treatment on minorities was driven by pure political considerations rather than by different fertility rates or sex ratios across ethnic groups (Greenhalgh, 2003). Hence, the threats of political economy and selection problems to the validity of a DD estimator discussed in Meyer (1995) can be ignored in our estimation.

Second, to illustrate the comparability of sex ratios across ethnic groups, Figure 2 depicts sex ratios for the Han and other minorities by birth year. It is important to observe that the

\footnotetext{
${ }^{16}$ Since the dependent variable is a dummy, a logit model would seem to be a natural choice. However, a linear probability model facilitates the interpretation of our DD estimates as shown above. Furthermore, because all explanatory variables in our regression equation are dummies for mutually exclusive and exhaustive categories, the model is saturated. The linear probability model is thus general because the fitted probability is simply the average within each cell defined by different values of $H_{i}, T_{i}$, and $X_{i}$. They are all dummy variables. We need not worry about fitted probabilities falling out the unit interval (Wooldridge, 2002). Moreover, the major results in our paper are confirmed when we use a logit model.

${ }^{17}$ Besley and Case (2000) address the endogeneity in the implementation of policies in natural experiment studies.
} 
time series pattern of sex ratios of minorities closely followed that of the Han Chinese's during the whole pre-policy change period from 1949 to the late 1970s. This situation substantially favors our empirical design because the comparison group of minorities has a distribution of outcomes very close to that of the treatment group of the Han Chinese during the pre-policy change period (Meyer, 1995).

Third, a common identifying assumption in a quasi-experiment design is the absence of omitted interactions. In other words, there are no omitted variables that changed the outcomes between treatment and comparison groups in different ways during the post-policy change period (Meyer, 1995). Fortunately, several features of our empirical design facilitate robust tests of the validity of this assumption in our DD estimates. We test and discuss the robustness of our DD estimates extensively in Section 7.

\subsection{Data Description}

The $1 \%$ sample of the 1990 Chinese population census, which is the fourth census conducted by the National Bureau of Statistics (NBS), is employed to implement the DD estimation discussed above. There are several reasons for using the data from the 1990 census. First of all, to evaluate the effect of the one-child policy on sex ratios at the national level, the advantage of using census data is self-evident compared to other survey data which are conducted at the provincial level, or even at the county level. Second, in contrast to the third population census in 1982, the 1990 census allows an appropriately lagged length of time for the evaluation of the policy effect, because 10 years had already passed after the enactment of the one-child policy in 1979. Third, before the 1990s, the household registration (Hukou) system in China was still strictly regulated, and thus there was little household mobility. Hence, the registration type (agricultural vs. non-agricultural Hukou) and other geographic information were very likely to remain unchanged.

Our empirical analysis is mainly conducted on two subsamples drawn from the 1990 census data set. Sample 1 includes all children born after 1972 with ethnic, gender, age, 
registration type, and geographic information. ${ }^{18}$ Sample 2 restricts Sample 1 to those children satisfying the following conditions: (i) sons or daughters of the household head; (ii) with complete information about the mother, father, and siblings; (iii) mother's age ranges from 20 to 3819

Table 1 gives variable definitions and summary statistics for two subsamples. Gender, Han, Rural, and Treat are four dummy variables indicating the sex, ethnic identity, household registration type, and birth cohort of the child surveyed. If the child is a Han boy with the agricultural Hukou, and was born after 1979, then the values of these four variables are all equal to one. In fact, there is another variable describing the household's location type, i.e., city, town, or village, in the 1990 census. However, since the registration type, Hukou, and the location type are highly correlated (the correlation coefficient is 0.97 ), only the household registration type is chosen to indicate the geographic characteristic of the child. Another reason for choosing the registration type is that the differential treatment of the one-child policy for households is based on registration type, and not on location type. ${ }^{20}$ The education levels of parents are classified into four categories: illiterate or semi-literate, primary school, junior high school, and senior high school or higher education ${ }^{21}$ Finally, the variable of Family size denotes the number of siblings of the child surveyed plus one, which amounts to the number of children of the household head.

The mean value of Gender in Sample 1, which is considered as the benchmark in the

\footnotetext{
${ }^{18}$ The reason that the birth year is truncated at 1972 is that children born in 1973 were just 17 years old in the census year of 1990. Since 18 is the legal minimum age for full-time work in China, most children younger than 18 are still economically dependent on and living with their parents.

${ }^{19}$ Because the census contains no information on children no longer living at home, excluding those households with children living outside home will result in a biased sample. Following Angrist and Evans (1998), we restrict mother's age to less than or equal to 38 to mitigate sample selection problem. Because the minimum age for marriage as prescribed by the Chinese Marriage Law is 20, the age cutoff is 17 for the eldest children of these women, and most of these children are still living with their parents.

${ }^{20}$ Considering the high correlation between the agricultural Hukou and the geographic location in rural areas, the interpretation of the variable Rural in the following part of the paper is exchangeable with the agricultural Hukou.

${ }^{21}$ There is a total of seven education levels in the 1990 census: Illiterate and semi-literate, primary school, junior high school, senior high school, technical school, junior college, and university or above. Since the sample size for senior high school and above is small, these four higher levels of education are grouped into one category: senior high school or higher education.
} 
empirical analysis, is 0.5196 . It implies that the mean value of sex ratios is 108.2 , which is higher than the biologically stable range of 104-107. As far as other variables are concerned, of those children in Sample 1, 90.29\% are Han Chinese, $84.09 \%$ with the agricultural Hukou, and $60.55 \%$ born in the post-policy change period. Compared to Sample 1, the mean value of Gender in Sample 2 is 0.5235, which implies that the mean value of the sex ratio is 109.9. The reason for this higher mean value of Gender in Sample 2 results from the higher mean value of Treat. In contrast to the fact that $60.55 \%$ of the children were born in the postpolicy change period in Sample 1, the mean value of Treat in Sample 2 is 0.8053 . It means that there is a higher proportion of children born in the post-policy change period in Sample 2 than in Sample 1. Since the sex ratio in the post-policy change period is higher than that in the pre-policy change period, the mean value of Gender is relatively higher in Sample 2. Table 1 also shows that mothers have an inferior educational attainment than fathers. Contrasting mothers and fathers, only $6.17 \%$ of surveyed children's fathers are illiterate or semi-literate, while there is as high as $23.27 \%$ of mothers falling into this category. Finally, the additional variable of Family size in Sample 2 indicates that each child has 1.26 siblings on the average in a household.

\section{Empirical Results}

This section systematically examines the effect of the one-child policy on the increase in sex ratios in the 1980s. We carry out the DD estimation of Equation (2) without and with the control vector of geographic indicators. Before presenting our DD estimates, Figure 2 plots sex ratios for the Han and minorities by birth cohort. While the sex ratio shows no systematical difference across ethnic groups before 1979, it is significantly and consistently higher for the Han Chinese throughout 1980s. In fact, the sex ratio gap across ethnic groups was on the average 0.73 (with a standard deviation of 2.08) in the pre-policy change period from 1950 to 1979 , and rose to 4.75 (with a standard deviation of 1.51) in the post-policy change period. 
Using Sample 1, Table 2 reports the DD estimates of the treatment effect of the onechild policy on the gender of the child by birth cohort. We report the mean value of gender for cohorts born in the pre-policy change period in row 1, and the mean value of gender for each cohort born in the post-policy change period in the rows below. In the last row, we report the average treatment effect of the one-child policy during the entire post-policy change period. In terms of columns, columns (1)-(2) report the mean value of gender for Han and other minorities respectively, and column (3) reports the difference between the two groups. Column (4) reports the difference-in-differences (Equation (1)), which equals column (3) minus the mean difference in gender during the pre-policy change period.

Consistent with Figure 2, Table 2 shows little difference between Han and other minorities in the gender during the whole pre-policy change period. The magnitude of the difference is close to zero, and is statistically insignificant. In contrast, the difference is as large as 0.011 for the whole post-policy change period, and is statistically significant at $1 \%$. It means that the sex ratio of Han is on the average 4.7 higher than that of minorities during the entire post-policy change period.$^{22}$ Moreover, the difference is consistently positive and mostly significant for each cohort born in the post-policy change period. Finally, column (4) shows that the DD estimates for all birth cohorts are all positive and mostly significant at conventional levels. The DD estimate for the entire post-treatment period, presented in the last row of column (4), is 0.0106 and is statistically significant at the $1 \%$ level.

Columns (5)-(6) report the DD estimates by including the provincial and rural indicators as control variables. Interestingly, we find that the DD estimates after controlling for provincial and rural indicators are quite close to the estimates without controlling for them (column (4)). It suggests that geographic characteristics are not important determinants of the change in the Han-minority sex ratio gap. The last row of columns (5)-(6) shows that the average treatment effect on the probability of being a boy is 0.0101 . It implies that the

\footnotetext{
${ }^{22}$ The difference in sex ratios between the Han and other minorities in the post-policy change period is given by $100 *[0.5234 /(1-0.5234)-0.5124 /(1-0.5124)]$, which equals 4.7 (note that 0.5234 and 0.5124 are from the last row of columns (1) and (2) in Table 2).
} 
one-child policy has increased the sex ratio by 4.4 , and $93.62 \%$ of the rise in sex ratios for

the Han Chinese throughout the 1980s can be accounted for by employing Equations (3)-(4). Using a Wald-type non-linear test as discussed in Subsection 3.1 above, we find the policy effect on sex ratio is statistically significant at the $1 \%$ level.

\section{The Effect of the One-Child Policy by Birth Order}

This section conducts the DD estimation by birth order. Based on Sample 2 with complete siblings' information, columns labeled as DD (1) at the first panel of Table 3 report our DD estimates by birth order without other control variables. We find that the magnitude of the DD estimate on the first birth parity is very small and is statistically insignificant. However, the DD estimate of the one-child policy is tripled for the second birth parity, and becomes marginally significant at the $10 \%$ level. Moreover, the DD estimate on the third and higher birth parities is as large as 0.0252 , which is statistically significant at the $5 \%$ level. Columns labeled as DD (2) at the first panel of Table 3 report DD estimates by birth order with other control variables. The control variables are rural, mother and father's education level, and provincial indicators. We find that the DD estimates by birth parity is robust to the inclusion of these control variables, and the DD estimate on the second birth parity even becomes statistically significant. Therefore, the estimated effect of the one-child policy in Table 2 is mainly reflected at the second and higher birth parities.

The variation pattern of our DD estimates across different birth parities is consistent with the one-child policy explanation of the increase in sex ratios. With the regulated birth quota of the one-child policy, the distortion of the sex ratio could be focused on the second and higher birth parities. The reason is that the required payment for the "above-quota" birth acts like a screener. Those parents risking the sanction to give a second or third birth should have stronger son preference than those who had only one child on average, and they are more likely to practice gender-selective abortion. Furthermore, the imposition of the above-quota birth sanction has indeed increased the probability of choosing the gender 
selection technology and practicing gender-selective abortion on the second and higher birth parity even in a homogenous case ${ }^{23}$

The second panel of Table 3 reports the DD estimates by both family size and birth order. It is interesting to note that the DD estimates exhibit a significant variation across family size and birth order. The DD estimate is positive and statistically significant for the second birth parity, while it is insignificantly negative for the first birth parity in two children families. If the family size is larger than two, the DD estimates are negative for the first two lower parities and positive for other higher parities. We further carry out the DD estimation by both birth order and gender composition of elder siblings in the third panel of Table 3. It is found that the DD estimate is only significant for those children born in the second parity with an elder sister and in higher birth parities with two elder sisters.

Caution is needed in interpreting the DD estimates in Table 3 because fertility (family size) is a choice variable. Therefore, we should look at the variation pattern of the DD estimates by birth order, family size, and gender composition of elder siblings rather than the DD estimate for a certain group of children. Summarizing from Table 3, we conclude that parents subject to the one-child policy are more likely to practice gender selection at the second or higher birth parities, especially when the first child is a girl or children at low birth parities are all girls.

\footnotetext{
${ }^{23} \mathrm{~A}$ simple calculation will make it clear. Since the increase of sex ratios is mainly driven by the rural subsample which will be demonstrated in the next section, and rural families could give birth to a second child if the first is a girl, parents in rural areas would be less likely to practice gender selection behavior on the first birth. However, if the second conception is a female, the parents would face the choice either practicing gender selective abortion or carrying the conception to term and then having a third child. Assume the benefit from giving a birth to a son is $\pi$, the cost of practicing gender selection is $c$, and the monetary sanction of an addition above-quota birth is $f$. For simplicity, we further assume that gender selection technology is perfect, rearing cost of the boy equals to the girl and it is normalized to zero, and the benefit of giving birth to a girl is also normalized to zero. Thus, if the conception is a female, the probability of choosing the gender selection technology is given by $P=P\left(\pi-c>\frac{1}{2} \pi-f\right)$, which is an increasing function of $f$. It means that, for given son preference and gender selection technology, the probability of practicing gender selection such as selective abortion at the second and higher birth parities is increasing with the decrease in fertility which is caused by the one-child policy.
} 


\section{The Effect of the One-Child Policy by Registration Type}

It is interesting to know how the policy effect on sex ratio has operated on different groups with different registration types. Although the one-child policy has been more strictly implemented in urban areas (Peng, 1996; Zhang and Spence, 1992), the sex ratio in rural areas may be more responsive to the one-child policy. On the one hand, the demand for sons is stronger in rural areas than in urban areas. For example, the agricultural work in rural areas is more labor intensive. The lack of retirement pensions in rural areas compels parents to have a son to avoid a miserable life in their old age. The Confucian tradition is stronger in rural areas because urban residents are more open-minded, and the continuation of the family's name is still considered as one of the most important responsibilities to predecessors in rural areas. On the other hand, the magnitude of the decrease of the total fertility rate is much bigger in rural areas than in urban areas after the introduction of the one-child policy. Since the effect of one-child policy on the increase in sex ratios is through the decrease of fertility and gender selection as discussed above, the policy effect on the sex ratio should be larger in rural areas than in urban areas. For example, while the total fertility rate in urban areas only decreased by $20 \%$ from 2.62 to 2.10 during the period of 1972-1990, it decreased by $46 \%$ from 5.83 to 3.12 in rural areas during the same period (NBS, 2002).

Another objective in estimating the treatment effect by registration type is to test the hypothesis of the rural household responsibility system reform. It has been suggested that the increase in sex ratios is associated with the economic reform in China, which may have changed the gender wage gap. One of the biggest policy reforms in the entire 1980s was the introduction of the rural household responsibility system. Moreover, it has been demonstrated that the adoption of this institutional reform had a significant impact on fertility behavior in rural China (Schultz \& Zeng, 1999).

During the same time, although no official document can be found to support different treatments of this institutional reform by ethnic groups, it is suggested that the timing of the adoption may depend on regional development levels (Lin, 1988). Since ethnic minorities, 
on the average, live in less developed regions in China, the timing of the adoption may be correlated with the distribution of minority residents. However, if our DD estimate is mainly picking up the effect of this factor, we would expect that the estimated policy effect should be insignificant in the rural subsample in the late 1980s, because almost all rural areas had adopted this system by 1988 (Lin, 1997).

Table 4 confirms the differential treatment effects of the one-child policy on the sex ratio imbalance for different groups of registration type, in which the same DD model has been implemented by using the rural and urban subsamples, respectively. Column (1) reports the DD estimates of the rural subsample. Consistent with the DD estimates in Table 2 for the whole sample, the DD estimates of the rural subsample are consistently positive at the significant level of $10 \%$ except for the birth cohort of 1982. In addition, after the inclusion of provincial indicators in column (2), our DD estimates are still significantly positive for most of birth cohorts.

In contrast to the rural subsample, columns (3)-(4) show that the DD estimates of the urban subsample are all insignificant at conventional levels except for the birth cohort of 1982. Moreover, the signs of the DD estimates in the urban sample are inconsistent across birth cohorts, and more than half of the DD estimates across birth cohorts are negative, though they are not statistically significant. In summary, the differential treatment effects on different subsamples suggest that the estimated effect of the one-child policy on the sex ratio imbalance in the whole sample of Table 2 is mainly driven by the rural subsample, because $84.09 \%$ of the children lived in rural areas. In addition, since the estimated treatment effects of the rural subsample are still highly significant for those birth cohorts in the late 1980s when almost all of the Chinese rural areas had adopted the household responsibility system, our DD estimates are not likely to be confounded by this institutional reform in rural areas. ${ }^{24}$

\footnotetext{
${ }^{24}$ Considering different sample sizes between rural and urban subsamples, we have applied the bootstrap method to generate standard errors and $t$-statistics in the rural subsample of Table 6 . The results are very similar. The table with bootstrapped $t$-statistics are available upon request.
} 


\section{Robust Analysis}

Although the previous analysis has identified the one-child policy as the main culprit for the increase in sex ratios in China, we need to ensure that our DD estimates are not mainly picking up the effect of other omitted policy shocks or socioeconomic changes. This section carries out the robust analysis. We first conduct the DD estimations for alternative dependent variables; we then analyze the time pattern of the DD estimates by birth year; finally, we carry out the DD estimation by provinces and autonomous regions, respectively.

\subsection{The DD Estimates for Other Outcome Variables}

The key identification assumption of the DD estimator is that there should no other policy shocks or changes in socioeconomic variables during the post-treatment period that have affected the gender selection behavior of the Han and minorities differently. Although we do not know any such kind of unobservable shocks or changes a priori, the validity of our DD identification can be justified as follows. If the DD estimate on the sex ratio is due to something other than the one-child policy (e.g. the economic reform which might have affected the Han and minorities differently), the impact should also manifest on other aspects. Thus, we also provide the DD estimate for other outcome variables covering family structure, mother's age at the first birth, parental education and labor market behaviors. To validate our DD identification, we expect that the DD estimates for these variables would be zero.

Table 5 reports the DD estimates for other outcome variables. It is reassuring to find that all DD estimates are statistically insignificant except for mother's education in the rural sample ${ }^{25}$ Considering the huge sample size, we conclude that there is no difference in changes between the Han and minorities in terms of family structure, mother's age at the first birth, father's education, and parental labor market behaviors. As for mother's education, it is noted that the estimated coefficient is small. In addition, the literature suggests that the increase of mother's education, relative to father's, enhances mother's bargaining power

\footnotetext{
${ }^{25}$ As discussed in the previous section, the effect of the one-child policy on sex ratio imbalance mainly happened in rural areas. Thus, we focus on the rural sample.
} 
within the household, and thus leads to a weakened preference for boys (Thomas, 1994; Behrman and Rosenzweig, 2002). Therefore, the fact that mother's education increases more for the Han than minorities would bias downward our DD estimates of the effect of one-child policy, if any. In other words, the DD estimate of the one-child policy on the sex ratio would have been larger without the increased female education of the Han relative to the minorities.

\subsection{The Time Pattern of the DD estimates by Birth Year}

This section systematically examines the time pattern of the DD estimates in the post-policy change period which is used to distinguish the one-child policy story from other competing hypotheses. As we have discussed earlier, the multiple pre- and post-policy change periods of our data set provide an opportunity to check the robustness of our quasi-experiment design (Meyer, 1995). We have discussed the co-movement of sex ratios across ethnic groups during the entire pre-policy change period in Subsection 3.1, which strongly establishes the comparability between the Han and other minorities.

It has been suggested that the spread of modern gender selection technologies, such as ultrasound B machines, may be responsible for the increase in sex ratios in China (Das Gupta, 2005; Gulmoto, 2009; Zeng et al., 1993). However, considering the fact that both the Han Chinese and minorities have exposure to a similar change in gender selection technology, our DD estimates are conditional on the spread of modern gender selection technologies. In addition, even if the distribution of ultrasound B machines was unbalanced across ethnic groups, and our DD estimates was confounded with this unbalanced distribution, we could expect a dynamically converging time pattern of the DD estimates during the post-policy change period.

Considering that the scan fee was relatively expensive for residents living in rural and remote areas in the early 1980s, ultrasound B machines were likely to have been first introduced to relatively wealthier regions, such as big cities, and eastern and coastal areas, where the majority of residents are Han. Thus, the Han Chinese may have had access to ultra- 
sound B machines earlier. However, the difference in the probability of access to this modern machine across ethnic groups should have been decreasing, because China had begun the introduction of ultrasound B machines on a large scale in 1982, and reached the peak of the importation of this machine during the period 1985-1989. In addition, China had produced over 10,000 ultrasound B machines per year in the late 1980s, which means there would have been about four machines in each county, and each county had actually been equipped with machines operated by proficient technicians by then (Zeng et al., 1993).

Figure 3 plots the time pattern of our DD estimates by birth year for the entire posttreatment period, in which DD1, DD2, and DD3 refer to the DD estimates in columns (4)-(6) in Table 2, respectively. Contradicting the ultrasound B hypothesis, the dynamic pattern of the estimated effect does not show any converging trend.

In addition, if our DD estimates in columns (4)-(6) of Table 2 are mainly driven by different timings of accessing to ultrasound $\mathrm{B}$ machines between the Han and minorities, the time pattern of the differences between columns (4) and (5)-(6) should also exhibit a converging trend. Under the ultrasound B machine story, the geographic location, which determines the probability of access to the machine between the Han and other minorities, is assumed to be the driving force underlying our DD estimates. Thus, the difference between our DD estimates without and with controlling for geographic location should be bigger in the early 1980s when ultrasound B machines were first available for the Han who mainly lived in eastern and coastal areas. These differences should be smaller when ultrasound B machines were widespread and the difference in accessing them between the Han and other minorities decreased in the late 1980s.

Figure 4 plots the dynamic pattern of the difference of our DD estimates without and with geographic indicators by birth year. Contrary to the prediction by the ultrasound B machine story, the differences between columns (4) and (5)-(6) in Table 2 exhibit no converging pattern at all.

In contrast to the ultrasound B machine story, the time patterns of both the DD estimates 
in Figure 3 and the differences of the DD estimates in Figure 4 are exactly consistent with the implementation stages and affirmativeness of the one-child policy in the 1980s. First, the rough "U" shape of the time pattern of the DD estimates for the entire 1980s just reflects the fact that the one-child policy was strict in the earlier 1980s; then the enactment of Central Document 7 relaxed the strictness of the one-child policy to a certain extent in 1984; and finally began to tighten it up in the late 1980s (Hardee-Cleaveland \& Banister, 1988; Scharping, 2003; Yang \& Chen, 2004).

Second, the time pattern of our DD estimates is surprisingly consistent with Scharping's (2003) classification of the stages of the one-child policy. In Scharping (2003), the entire post-policy change period is classified into four phases: Drums and gongs (the campaign from 1979 to 1983); small holes and big gaps (the relaxation from 1984 to 1985); tit for tat (the controversy from 1986 to 1989); and law and order (the administration from 1990 to 1999). It is interesting to find that the first three stages are clear in the time pattern of our DD estimates in Figure $3{ }^{26}$ In addition, the three biggest inflexion changes in Figure 4 just correspond to the three biggest policy changes in 1982, 1984, and 1986 respectively. ${ }^{27}$

Third, the relatively mild differences of the DD estimates between columns (4) and (5)(6) in the first half of the 1980s (Figure 4) reflect the fact that the one-child policy was almost uniformly implemented across the nation, and that little difference was allowed across provinces and between rural and urban areas in its early stage. After the strong resistance encountered during the initial policy implementation process, especially in rural areas, the central government then began to allow differences across provinces, and had made a clear distinction between rural and urban areas in 1986 (Peng, 1996). In 1988, Peng Peiyun, then head of the National Family Planning Commission, admitted that the adoption of a uniform policy guideline was impossible across the whole country. Therefore, the inclusion of the

\footnotetext{
${ }^{26}$ It should be noted that the policy effect may be roughly lagged for one year for pregnancy time.

${ }^{27}$ In December 1982, the commitment for birth planning was unprecedentedly written in the revised Chinese Constitution Law, which decreed it as the citizens' duty and the task of lower level administrations. Considering the strong resistance encountered, Central Document 7 relaxed the rigid one-child policy in 1984. Then the resurgence of birth rates led to Central Document 13 issued in May 1986 calling for strict adherence to population targets.
} 
geographic and rural indicators should have affected the magnitude of the DD estimates in column (4) of Table 2 to a larger extent in the late 1980s.

Finally, comparing Figure 3 with Figure 4, we find that the two locally lowest DD estimates for birth cohorts of 1982 and 1986 in Figure 3 precisely correspond to two locally highest points in Figure 4, respectively. It means that the variation of the one-child policy across provinces and between rural and urban areas is bigger when the policy implementation is weaker. This corresponds to the general practice in the implementation of the one-child policy by the Chinese central government. When the rigid one-child policy was relaxed, the Central Committee of the Family Planning allowed different local formulas for incentives and sanctions based on different local conditions. However, when the Central Committee decided to tighten up the policy, a stringently unitary campaign was promoted across the nation (Scharping, 2003).

\subsection{The Geographic Pattern of the DD Estimates by Provinces and Autonomous Regions}

We have examined the robustness of our DD estimates across time in previous subsections. We now explore the geographic pattern of the DD estimates by provinces and autonomous regions. In China, the percentage of minorities living in five autonomous regions to the whole population of minorities is higher than $40 \%$, and these autonomous regions are geographically located at the western and southern parts of China. ${ }^{28}$ There had been unbalanced socioeconomic development across provinces and autonomous regions after the economic reform in the late 1970s. During the same time, the increase in sex ratios in China has been suggested to be correlated with socioeconomic development (Qian, 2008). Therefore, the benefit of estimating the treatment effect at the provincial or autonomous regional level is that the Han and minorities should be more homogeneously affected by the economic reform within the same area, and thus the interfering effect of socioeconomic development can be

\footnotetext{
${ }^{28}$ In the present paper, the 22 provinces and 4 municipalities in China are grouped together and all are treated as provinces. The five autonomous regions are Guangxi, Inner Mongolia, Ningxia, Tibet, and Xinjiang. The two Special Administrative Regions of Hong Kong and Macao are excluded in our analysis.
} 
held constant or eliminated.

Table 6 reports our DD estimates by province and autonomous region in the upper panel, and by each autonomous region in the lower panel. Columns (1)-(2) show that people living in provinces constitute a dominant share of $91.15 \%$ of the total population, where $93.59 \%$ is Han. Only $8.85 \%$ of the Chinese population live in the five autonomous regions, and almost $45 \%$ of the residents living there are minorities. Column (3) reports the DD estimates for the provinces and autonomous regions. We find that both DD estimates are positive and significant at a high level of 1\%. Furthermore, column (4) shows that these two DD estimates are robust to the inclusion of the rural indicator. The lower panel of Table 6 shows that the estimated treatment effects are positive for the autonomous regions except Tibet. The reason for the insignificant DD estimate for Tibet may be due to the fact that, as shown in column (2), there is only $0.35 \%$ of the children who are Han in Tibet (see column 2). Thus, essentially, the one-child policy has been exempted for most people in Tibet. The negative DD estimate for Tibet may actually reflect a weakening son preference with socioeconomic development. In summary, the geographic pattern in Table 6 further validates our quasiexperiment design.

An interesting finding is that the estimated treatment effect of the one-child policy is bigger in autonomous regions than in provinces. A possible explanation may be that the agricultural sector is the primary sector in these five regions. Hence, the gender gap of labor productivity in autonomous regions is on the average higher than in the rest of China because of the labor intensive nature of the agricultural work. A complementary explanation comes from the fact that the Han Chinese living in autonomous regions may be subject to a stricter one-child policy than their counterparts in provinces. Indeed, many of the Han Chinese living in the autonomous regions are dispatched by the government and work in the public sectors, and the one-child policy has been implemented more stringently in these sectors (Peng, 1996).

In summary, our robust analysis indicates that the DD estimates of the one-child policy 
effect on sex ratio are unlikely to pick up the effects of other policy shocks or socioeconomic changes, which may affect the gender selection behavior such as gender-selective abortion between the Han and minorities differently.

\section{DD Estimates Using the 2000 Census and the 2005 Mini-Census}

This section presents the DD estimates using the 2000 census and the 2005 mini-census. In China, the sex ratio at birth shows a dramatically increasing trend during 1990-2005. Although the DD method requires birth cohorts to be near the implementation year of the one-child policy, exploring the policy effect in the 1990s onwards is interesting. As in the foregoing analysis, this section treats the 1973-1979 birth cohort in the 1990 census as the group born prior to the one-child policy. In the 2000 census, we use the 1991-2000 birth cohort as the group born in the 1990s. Similarly, we use the 2001-2005 birth cohort in the 2005 mini-census.

Table 7 reports the estimation results using the 2000 census and the 2005 mini-census, respectively. Column (1) shows that compared with the birth cohort before 1980, the onechild policy has increased the probability of being a boy by as large as 1.52 percentage points in the 1990s. Using Equation (3), we calculate that the policy effect on sex ratios is about 6.98, which is statistically significant at $1 \%$ level. Using Equation (4), we find that the effect of the one-child policy accounts for $57.12 \%$ of the total increase in sex ratios during the 1990s. From columns (2)-(3), we find that the policy effect is robust to the inclusion of provincial and rural dummies. Similarly, column (4) shows that the one-child policy increases the probability of being a boy by 1.58 percentage points. This implies that the one-child policy has increased the sex ratio by 7.01 in 2001-2005, accounting for $53.59 \%$ of the total increase in sex ratios during the same period.

Table 8 summarizes the effects of the one-child policy on sex ratios across the 1990 census, the 2000 census, and the 2005 mini-census. Column (1) reports the actual sex ratios at different periods. Column (2) calculates the total increases in sex ratios for two adjacent 
periods. The estimated effects of the one-child policy on the sex ratio in different periods are reported in column (3). It is noted that the effect of one-child policy on sex ratios has increased by 2.28 from the 1980s to the 1990s (i.e., 6.98-4.40), and then it leveled off in 20012005 (i.e., 7.01-6.98). The increase in the policy effect on sex ratios in the 1990s onwards may be attributable to the 1.5-child policy, which was more prevalent after 1990. Zeng (2007, 2009) analyzes the structural impact and the implicit psychological effect induced by the 1.5child policy on sex ratios. For example, the 1.5-child policy suggests that the government implicitly agrees that a girl's value is half that of a boy. Such implicit psychological effects, together with the traditional strong son preference, lead a rural resident whose first child is a girl to conduct prenatal gender selection to have at least one boy ${ }^{29}$

Columns (4) of Table 8 shows that the percentage of increase in sex ratios accounted for by the one-child policy has substantially decreased from the 1980s to the 1990s. Although the one-child policy accounted for a dominant share (94\%) of the increase in sex ratios in the 1980 s, it only explained $57 \%$ and $54 \%$ of the increases in the 1990s and 2001-2005, respectively. This implies that the continuing increase in sex ratios in the 1990s onwards is mainly caused by other factors such as socioeconomic development rather than the one-child policy.

As discussed above, given son preference and gender selection technology, the frequency or intensity of gender selection is different at different fertility levels; thus, the sex ratio also becomes different. Specifically, ceteris paribus, the sex ratio increases as fertility decreases. Of course, lower fertility with desired gender (boys) in the population can only be realized by resorting to gender selection at an earlier time or at a more intensified pace. Following this logic, the steady increase in sex ratios after 1990 has been a result of the steady decrease in fertility during the same period. The total fertility rate decreased from 2.46 in 1990 to

\footnotetext{
${ }^{29} \mathrm{Guo}(2005)$ and $\mathrm{Gu}$ et al. (2008) have analyzed fertility rates and sex ratios across different policy regimes. It would be interesting to explore the causal effects of the 1-, 1.5-, and 2-child policies on sex ratios among the Han Chinese. However, the 1-, 1.5-, and 2-child policies among the Han Chinese are suspected to be endogenously imposed. In contrast, the differential treatment of the policy across ethnic groups is evidently exogenously imposed.
} 
1.80 in 2000 . Therefore, any factor that has led to a decrease in fertility has also driven up sex ratios. The one-child policy had played a major role in decreasing fertility in the 1980s; hence, it was the dominant driver of the increase in sex ratio during this period. The importance of the one-child policy may have lessened in the decline of fertility rates in the 1990s onwards, and correspondingly, its importance in increasing sex ratios may have likewise decreased. The rapid economic growth in the 1990s, for example, increased the private monetary and opportunity cost of childbearing. During the same time, the emphasis on human capital pushed parents to invest more on their children's education. Therefore, socioeconomic development decreased fertility in the 1990s. Low fertility, strong son preference, and the availability of modern gender selection technology lead parents to practice gender selection or gender-selective abortion more likely.

\section{Conclusion}

Exploiting a unique feature of the one-child policy (i.e., it was only applied to the Han Chinese), this paper has constructed a DD estimator to identify the causal relationship between the one-child policy and the recent increase in sex ratios in China. Based on the 1990 Chinese population census, the estimated effect of the one-child policy on the probability of being a boy is as large as 1.01 percentage points in the 1980s. This implies that the strict enforcement of the one-child policy has causally increased the sex ratio by 4.4, accounting for about $94 \%$ of the increase in sex ratios throughout the 1980s. Further exploration reveals that the policy effect is mainly driven by second and higher birth parities, and by rural residents. Moreover, several robust tests indicate that the DD estimates are not likely confounded by other policy shocks or socioeconomic changes. We have also conducted the DD estimation by using both the 2000 census and the 2005 mini-census. The estimates imply that the one-child policy has increased the sex ratio by about 7.0 for the 1991-2005 birth cohort, accounting for about $57 \%$ and $54 \%$ of the increases in sex ratios for the 1990s and 2001-2005 birth cohorts, respectively. 


\section{References}

[1] Angrist, J. (2002). How Do Sex Ratios Affect Marriage and Labor Markets? Evidence from America's Second Generation. Quarterly Journal of Economics, 117(3), 997-1038.

[2] Angrist, J., \& Evans, W. (1998). Children and Their Parent's Labor Supply: Evidence from Exogenous Variation in Family Size. American Economic Review, 88(3), 450-477.

[3] Angrist, J., \& Krueger, A. (1999). Empirical Strategies in Labor Economics. In Orley Ashenfelter and David Card, eds., Handbook of Labor Economics. Volume 3A. Amsterdam: North-Holland.

[4] Banister, J. (2004). Shortage of Girls in China Today. Journal of Population Research, $21(1), 19-45$.

[5] Becker, G. S. (1991). A Treatise on the Family. Enlarged edition, Cambridge, Mass: Harvard University Press.

[6] Behrman, J. R., \& Rosenzweig, M. R. (2002). Does Increasing Women's Schooling Raise the Schooling of the Next Generation? American Economic Review, 92(1), 323-334.

[7] Ben-Porath, Y., \& Welch, F. (1976). Do Sex Preferences Really Matter? Quarterly Journal of Economics, 90(2), 285-307.

[8] Besley, T., \& Case, A. (2000). Unnatural Experiments? Estimating the Incidence of Endogenous Policies. Economic Journal, 110(467), 672-694.

[9] Blau, F. D., \& Kahn, L. M. (1997). Swimming Upstream: Trends in the Gender Wage Differential in the 1980s. Journal of Labor Economics, 15(1), 1-42.

[10] Cai, F., Park, A., \& Zhao, Y. (2008). The Chinese Labor Market. In Loren Brandt and Thomas Rawski, eds., China's Great Economic Transformation. London: Cambridge University Press. 
[11] Chiappori, P.-A., Fortin, B., \& Lacroix, G. (2002). Marriage Market, Divorce Legislation and Household Labor Supply. Journal of Political Economy, 110(1), 37-72.

[12] Chu, J. (2001). Prenatal Sex Determination and Sex-Selective Abortion in Rural Central China. Population and Development Review, 27(2), 259-281.

[13] Coale, A. J., \& Banister, J. (1994). Five Decades of Missing Females in China. Demography, 31(3), 459-479.

[14] Das Gupta, M. (2005). Explaining Asia's "Missing Women": A New Look at the Data. Population and Development Review, 31, 529-535.

[15] Dreze, J., \& Khera, R. (2000). Crime, Gender, and Society in India: Insights from Homicide Data. Population and Development Review, 26(2), 335-352.

[16] Duflo, E. (2003). Grandmothers and Granddaughters: Old-Age Pensions and Intrahousehold Allocation in South Africa. World Bank Economic Review, 17(1), 1-25.

[17] Ebenstein, A. Y. (2009). The "Missing Girls" of China and the Unintended Consequences of the one-child Policy. Journal of Human Resources. Forthcoming.

[18] Edlund, L. (1999). Son Preference, Sex Ratios, and Marriage Patterns. Journal of Political Economy, 107(6), 1275-1304.

[19] Edlund, L., Li, H., Yi, J., \& Zhang, J. (2008). Sex Ratio and Crime: Evidence from China's One-Child Policy. IZA Working Paper 3214.

[20] Foster, A. D., \& Rosenzweig, M. R. (1999). Missing Women, the Marriage Market and Economic Growth. Brown University Working Paper.

[21] Greenhalgh, S. (2003). Science, Modernity, and the Making of China's One-Child Policy. Population and Development Review, 29(2), 163-201. 
[22] Gu, B., Song, J., Liu, S., Wang, J., \& Jiang, L. (2008). The Practice and Enlightenment of the Two-Child Policy Regime (er hai sheng yu zheng ce di qu de shi jian ji qi shi). Population Research (Ren Kou Yan Jiu), 32(4), 33-49.

[23] Guilmoto, C. Z. (2009). The Sex Ratio Transition in Asia. Population and Development Review, 35(3), 519-549.

[24] Guo, Z. (2005). A Demographic Analysis According to the One-Child Policy Regimes Based on the 2000 Population Census (2000 nian ren kou pu cha an sheng yu zheng ce lei xing de ren kou fen xi). In A Report of a National Major Research Project for the 2000 Population Census (2000 nian ren kou pu cha guo jia zhong dian ke ti yan jiu bao gao), edited by The Census Office of the Chinese State Council and National Bureau of Statistics. China Statistics Press.

[25] Gustafsson, B., \& Li, S. (2000). Economic Transformation in Urban China and the Gender Earnings Gap. Journal of Population Economics, 13(2), 305-330.

[26] Hardee-Cleaveland, K., \& Banister, J. (1988). Fertility Policy and Implementation in China, 1986-88. Population and Development Review, 14(2), 245-286.

[27] Hesketh, T., Lu, L., \& Xing, Z. W. (2005). The Effect of China's One-Child Family Policy after 25 Years. New England Journal of Medicine, 353(11), 1171-1176.

[28] Hesketh, T., \& Xing, Z. W. (2006). Abnormal Sex Ratios in Human Populations: Causes and Consequences. Proceedings of the National Academy of Sciences, 103(36), 1327113275 .

[29] Hudson, V. M., \& Boer, A. D. (2002). A Surplus of Men, A Deficit of Peace: Security and Sex Ratios in Asia's Largest States. International Security, 26(4), 5-38.

[30] Li, G. (2002). Effects of the One-Child policy on the Number and Sex Composition of Children in China. University of Washington Working Paper. 
[31] Li, H., \& Zhang, J. (2009). Testing the External Effect of Household Behavior: The Case of the Demand for Children. Journal of Human Resources, 44(4), 890-915.

[32] Li, H., \& Zhang, J. (2008). Fines, Limited Liability and Fertility. The Chinese University of Hong Kong Working Paper.

[33] Li, H., \& Zhang, J. (2007). Do High Birth Rates Hamper Economic Growth? Review of Economics and Statistics, 89(1), 110-17.

[34] Lin, J. Y. (1988). The Household Responsibility System in China's Agricultural Reform: A Theoretical and Empirical Study. Economic Development and Cultural Change, 36(3), S199-224.

[35] Lin, J. Y. (1997). The Role of Agriculture in the Transition Process in China. In J. Kydd, S. Davidson, M. Mackay and T. Mech, eds., The Role Agriculture in theTtransition Toward a Market Economy. New York: United Nations.

[36] Lin, M. J., \& Luoh, M. C. (2008). Can Hepatitis B Mothers Account for the Number of Missing Women? Evidence from Three Million Newborns in Taiwan. American Economic Review, 98(5), 2259-2273.

[37] Meng, X. (1998). Male-Female Wage Determination and Gender Wage Discrimination in China's Rural Industrial Sector. Labour Economics, 5(1), 67-89.

[38] Meyer, B. D. (1995). Natural and Quasi-Experiments in Economics. Journal of Business and Economic Statistics, 13(2), 151-161.

[39] National Bureau of Statistics (NBS). 2002. Tabulation on the 2000 Population Census of the People's Republic of China [2000 nian ren kou pu cha tong ji zi liao hui bian]. Beijing: China Statistics Press.

[40] Oster, E. (2005). Hepatitis B and the Case of the Missing Women. Journal of Political Economy, 113(6), 1163-1216. 
[41] Oster, E., \& Chen, G. (2008). Hepatitis B Does Not Explain Male-Biased Sex Ratio in China. NBER Working Paper 13971.

[42] Park, C. B., \& Han, J. Q. (1990). A Minority Group and China's One-Child Policy: The Case of the Koreans. Studies in Family Planning, 21(3), 161-170.

[43] Peng, P. (ed.) (1996). Family Planning Encyclopedia of China [zhong guo ji hua sheng yu quan shu]. Beijing: China Population Press.

[44] Porter, M. (2007). The Effects of Sex Ratio Imbalance in China on Marriage and Household Bargaining. University of Chicago Working Paper.

[45] Porter, M. (2008). How Marriage Market Conditions in China Influence Intergradational Transfers. University of Chicago Working Paper.

[46] Qian, N. (2008). Missing Women and the Price of Tea in China: The Effect of SexSpecific Earnings on Sex Imbalance. Quarterly Journal of Economics, 123(3).

[47] Rao, V. (1993). The Rising Price of Husbands: A Hedonic Analysis of Dowry Increases in Rural India. Journal of Political Economy, 101(4), 666.

[48] Rosenzweig, M. R., \& Schultz, T. P. (1982). Market Opportunities, Genetic Endowments, and Intrafamily Resource Distribution: Child Survival in Rural India. American Economic Review, 72(4), 803-815.

[49] Rozelle, S., Dong, X., Zhang, L., \& Mason, A. (2002). Gender Wage Gaps in PostReform Rural China. Pacific Economic Review, 7(1), 157-179.

[50] Scharping, T. (2003). Birth Control in China, 1949-2000 : Population Policy and Demographic Development. London; New York: Routledge.

[51] Schultz, T. P., \& Zeng, Y. (1999). The Impact of Institutional Reform from 1979 through 1987 on Fertility in Rural China. China Economic Review, 10(2), 141-160. 
[52] Sen, A. (1990). More than 100 Million Women are Missing. New York Review of Books.

[53] Short, S. E., \& Zhai, F. (1998). Looking Locally at China's One-Child Policy. Studies in Family Planning, 29(4), 373-374.

[54] Thomas, D. (1994). Like Father, Like Son; Like Mother, Like Daughter: Parental Resources and Child Height. Journal of Human Resources, 29(4), 950-988.

[55] Tuljapurkar, S., Li, N., \& Feldman, M. W. (1995). High Sex Ratios in China's Future. Science, 267(5199), 874-876.

[56] Wooldridge, J. M. (2002). Econometric Analysis of Cross Section and Panel Data. Mass: MIT Press.

[57] Wei, S., \& Zhang, X. (2008). Sex Ratio Imbalances Stimulate Savings Rates: Evidence from the Missing Women in China. Columbia University Working Paper.

[58] Yang, D. T., \& Chen, D. (2004). Transformations in China's Population Policies and Demographic Structure. Pacific Economic Review, 9(3), 269-290.

[59] Zeng., Y., Ping, T., Baochang, G., Yi, X., Bohua, L., \& Yongping, L. (1993). Causes and Implications of the Recent Increase in the Reported Sex Ratio at Birth in China. Population and Development Review, 19(2), 283-302.

[60] Zeng, Y. (2007). Options for Fertility Policy Transition in China. Population and Development Review, 33(2), 215-246.

[61] Zeng, Y. (2009). Soft-landing of the Two-child plus Spacing Policy is Helpful to Resolve the Problems of High Sex Ratio at Birth in China (er hai wan yu ruan zhe lu fang an you li yu jie jue wo guo chu sheng xing bie bi pian gao wen ti). Social Science (she hui ke xue), 8, 54-59.

[62] Zhang, J., \& Spencer, B. (1992). Who Signs China's One-Chid Certificate, and Why? Journal of Population Economics, 5, 203-215. 
[63] Zhang, J., Han, J., Liu, P., \& Zhao, Y. (2008). Trends in the Gender Earnings Differential in Urban China, 1988-2004. Industrial and Labor Relations Review, 61(2), 224-243. 
Figure 1: Sex ratios by birth cohorts

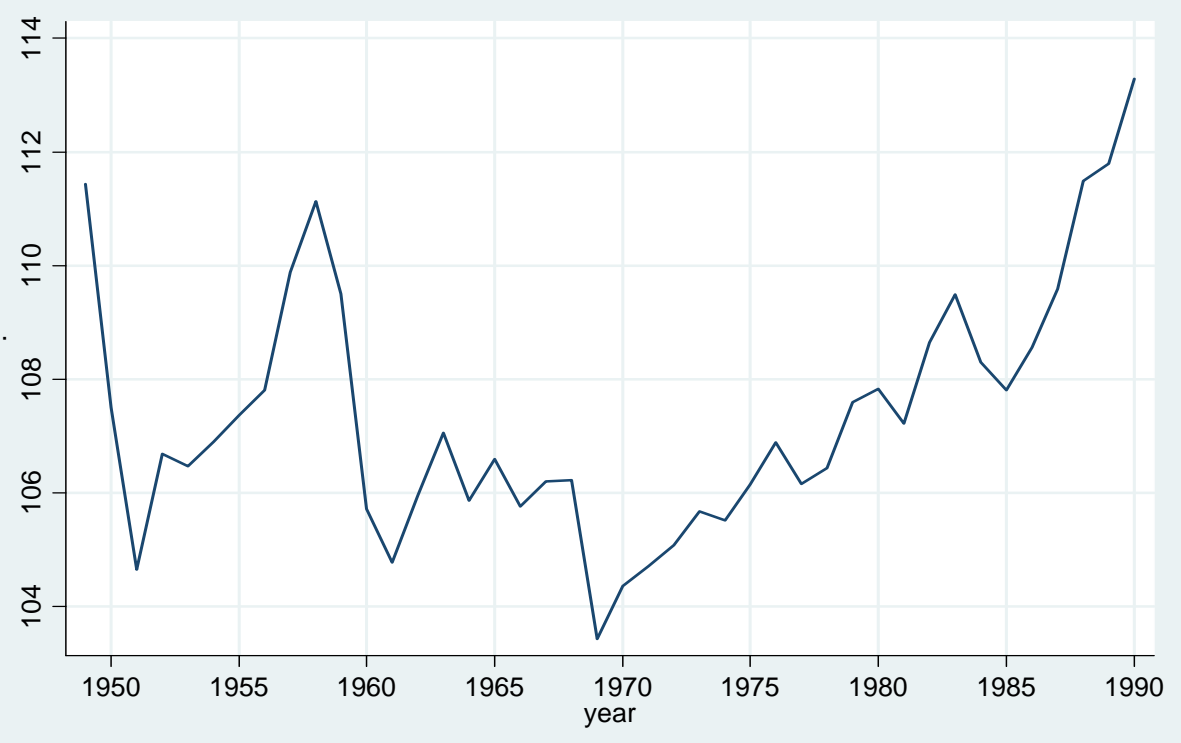

Note: Calculation is based on the 1990 Chinese population census (1\% sample).

Figure 2: Sex ratios by Han and other minorities

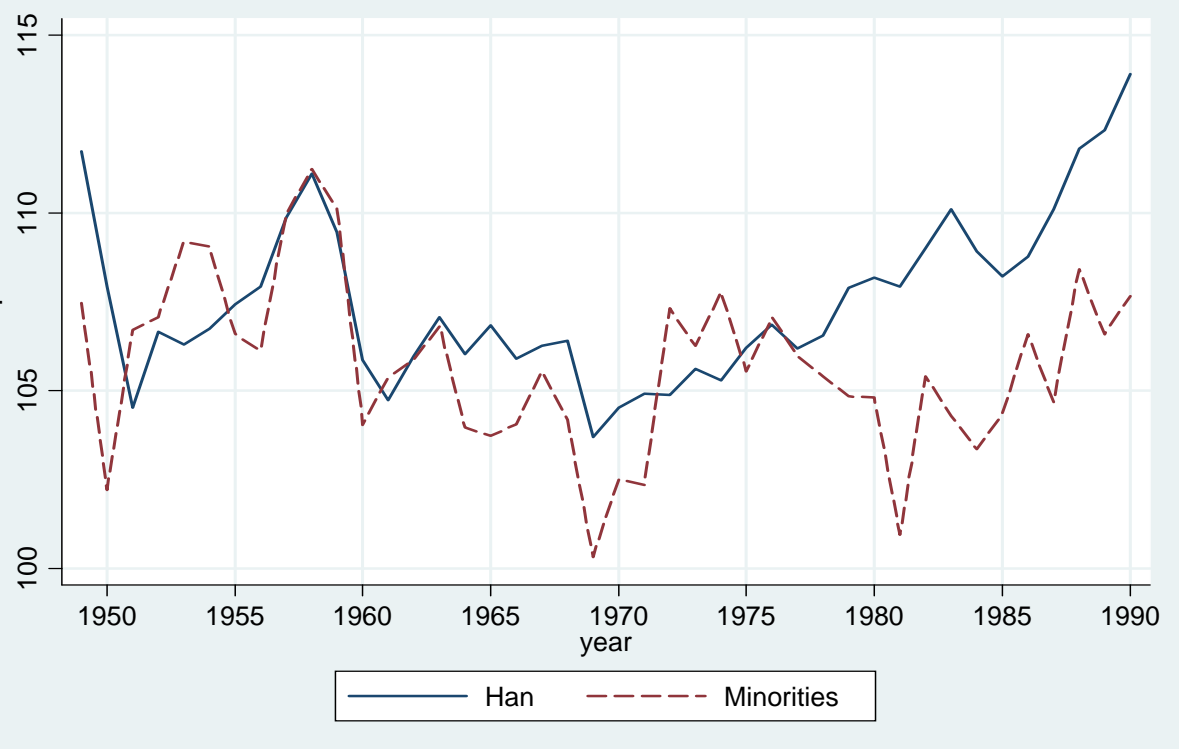

Note: Calculation is based on the 1990 Chinese population census (1\% sample). 
Figure 3: DD estimates by birth year

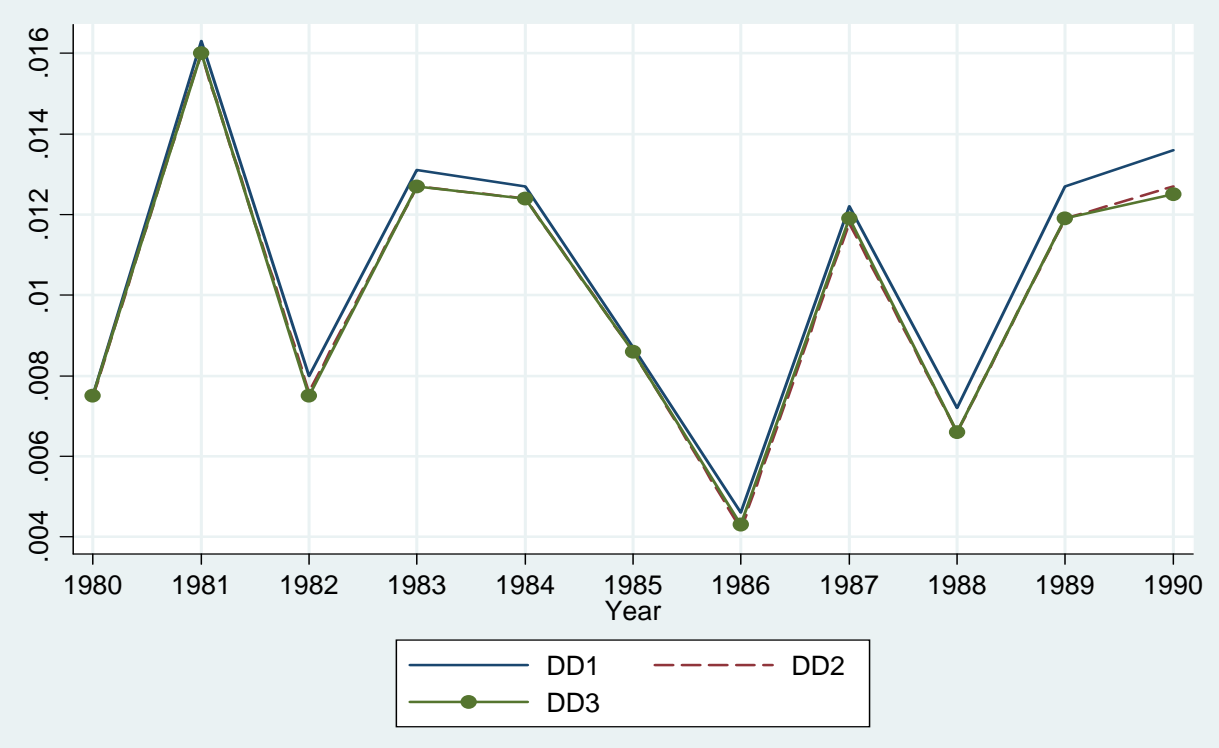

Note: DD1 refers to DD estimates without any control variables (column 4 in Table 2); DD2 refers to DD estimates controlling for provincial indicators (column 5 in Table 2); DD3 refers to DD estimates controlling for both provincial and rural indicators (column 6 in Table 2).

Figure 4: Differences between DD estimates without and with provincial and registration type indicators

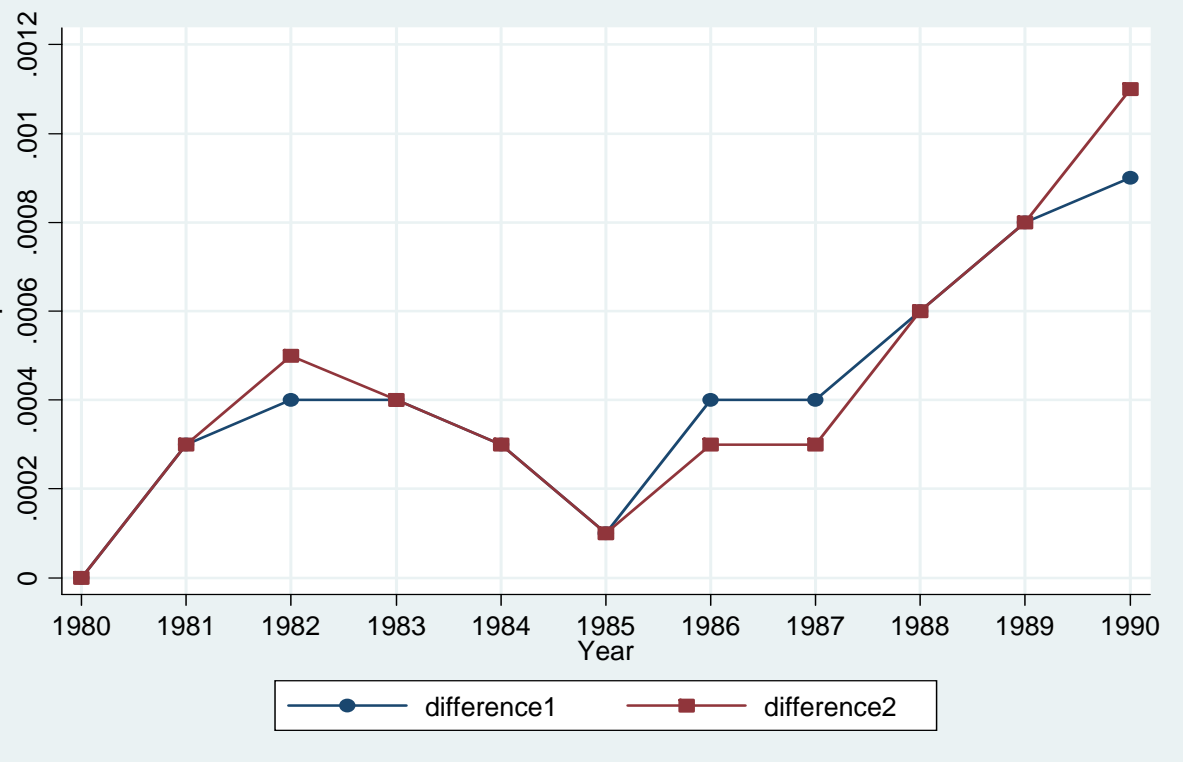

Note: Difference 1 refers to the difference between the DD estimates without and with provincial indicators (the difference between columns 4 and 5 in Table 2); Difference 2 refers to the difference between the DD estimates without and with both provincial and rural indicators (the difference between columns 4 and 6 in Table 2). 


\section{Appendix}

Figure A1: Chinese urban gender wage gap 1988-2004

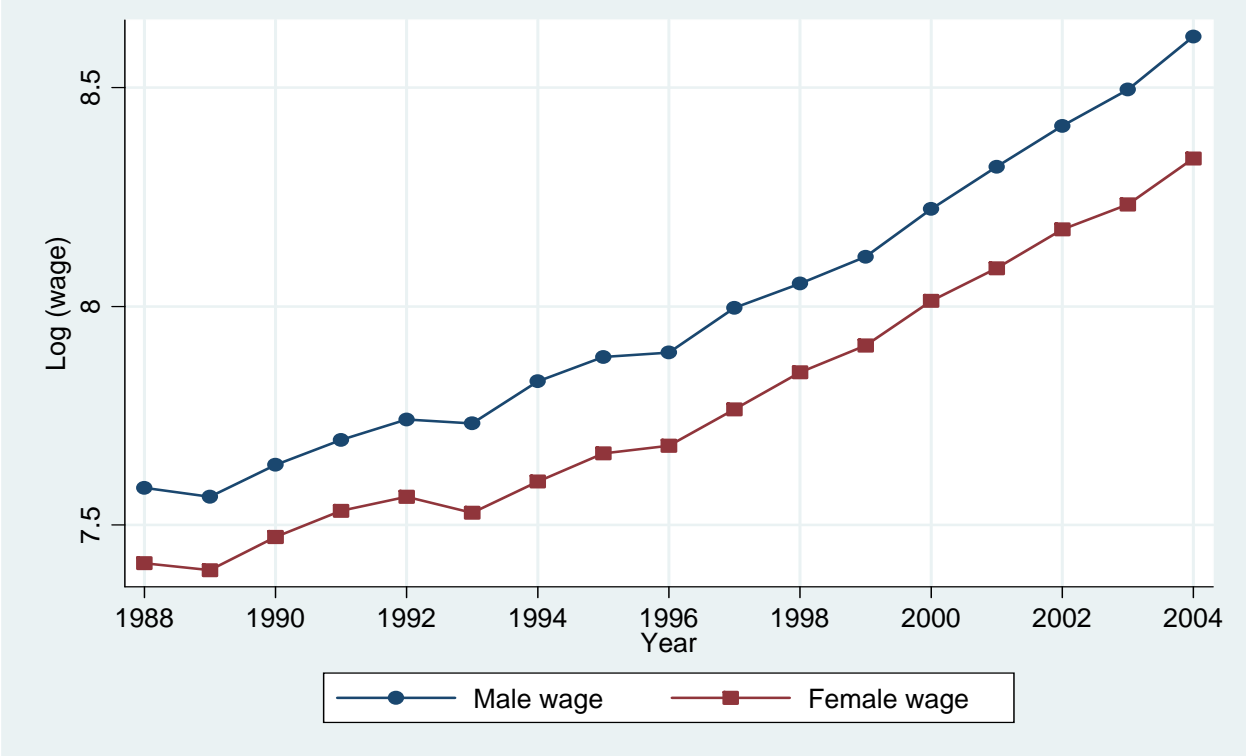

Note: The calculation is based on Table 1a in Zhang, J., Han, J., Liu, P., \& Zhao, Y. (2008), Trends in the Gender Earnings Differential in Urban China, 1988-2004. Industrial and Labor Relations Review, 61(2), 224-243. 
Table 1: Variable definition and summary statistics

\begin{tabular}{|c|c|c|c|c|c|}
\hline \multirow[b]{2}{*}{ Variables } & \multirow[b]{2}{*}{ Definitions } & \multicolumn{2}{|c|}{ Sample 1} & \multicolumn{2}{|c|}{ Sample 2} \\
\hline & & Mean & S.D. & Mean & S.D. \\
\hline Gender & 1: male; 0: female & 0.5196 & 0.4996 & 0.5235 & 0.4994 \\
\hline Han & 1: Han; 0: national minorities & 0.9030 & 0.2960 & 0.9094 & 0.2871 \\
\hline Rural & 1: agricultural Hukou; 0: non-agricultural Hukou & 0.8409 & 0.3658 & 0.8625 & 0.3443 \\
\hline Treat & 1: born after 1979; 0: otherwise & 0.6055 & 0.4888 & 0.8053 & 0.3960 \\
\hline Mother illiterate & 1: illiterate or semi-literate; 0 : otherwise & & & 0.2327 & 0.4225 \\
\hline Mother primary & 1: primary school; 0: otherwise & & & 0.4224 & 0.4934 \\
\hline Mother junior & 1: junior middle school; 0 : otherwise & & & 0.2529 & 0.4347 \\
\hline Mother senior or higher & 1: senior middle school or higher education levels; 0 : otherwise & & & 0.0920 & 0.2890 \\
\hline Father illiterate & 1: illiterate or semi-literate; 0 : otherwise & & & 0.0618 & 0.2407 \\
\hline Father primary & 1: primary school; 0: otherwise & & & 0.3550 & 0.4785 \\
\hline Father junior & 1: junior middle school; 0 : otherwise & & & 0.4084 & 0.4915 \\
\hline Father senior or higher & 1: senior middle school or higher education levels; 0 : otherwise & & & 0.1748 & 0.3798 \\
\hline Family size & The number of siblings plus 1 for the child surveyed & & & 2.2647 & 1.0131 \\
\hline Number of observations & & & & & \\
\hline
\end{tabular}

Note: Sample 1 includes all children aged from 0 to 17 in the Chinese population census in 1990 (1\% sample) with age, gender, registration type and geographic location information. Sample 2 restricts Sample 1 to those children satisfying the following conditions: (i) sons or daughters of the household head; (ii) complete information of mother, father, and siblings; (iii) mother's age is ranging from 20 to 38. 
Table 2: Difference-in-Differences estimates of the effect of the one-child policy on the probability of being a boy

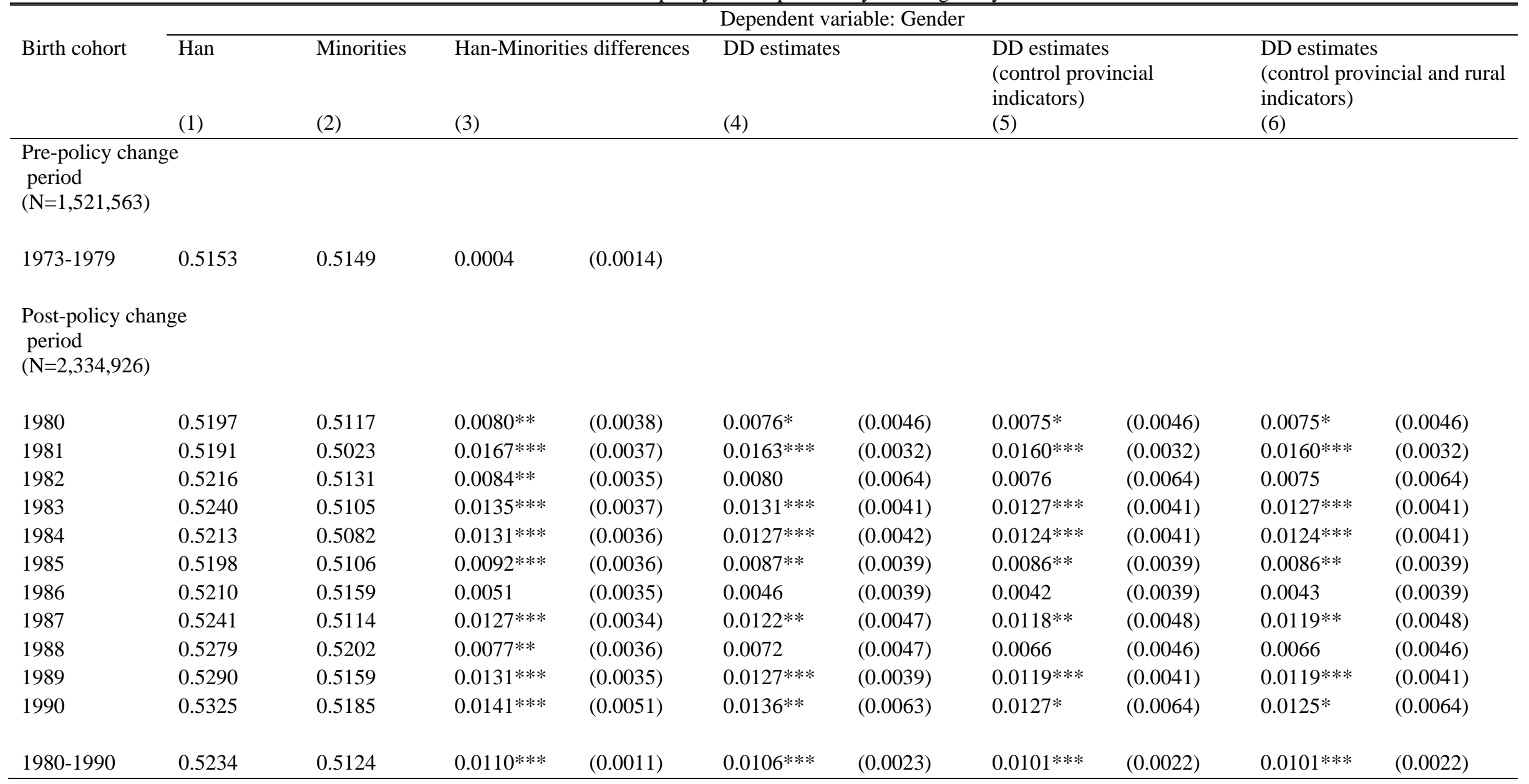

Note: Standard errors are in parentheses; * significant at $10 \%$; ** significant at $5 \%$; *** significant at $1 \%$. The dependent variable is a dummy indicating the gender of the child; it equals 1 if the child is a boy, otherwise 0. The data set used is Sample 1 with a total of 3,856,489 observations (see Table 1). Column (6) reports the DD estimates with the control vector of province dummies, and column (7) reports the DD estimates controlling for both province and rural dummies. 
Table 3: Difference-in-Differences estimates of the effect of the one-child policy on the probability of being a boy by birth order, family size, and gender composition of elder siblings

\begin{tabular}{|c|c|c|c|c|c|c|c|c|c|c|c|c|}
\hline & \multicolumn{4}{|c|}{ Birth order $=1$} & \multicolumn{4}{|c|}{ Birth order $=2$} & \multicolumn{4}{|c|}{ Birth order $>2$} \\
\hline & $\mathrm{DD}(1)$ & & $\mathrm{DD}(2)$ & & $\mathrm{DD}(1)$ & & $\mathrm{DD}(2)$ & & $\mathrm{DD}(1)$ & & $\mathrm{DD}(2)$ & \\
\hline \multicolumn{13}{|l|}{ By birth order } \\
\hline & 0.0034 & $(0.0043)$ & 0.0033 & $(0.0039)$ & 0.0095 & $(0.0061)$ & $0.0100^{*}$ & $(0.0061)$ & $0.0259 * * *$ & $(0.0071)$ & $0.0254 * * *$ & $(0.0078)$ \\
\hline \multicolumn{13}{|c|}{ By family size and birth order } \\
\hline Family size $=1$ & 0.0106 & $(0.0213)$ & 0.0117 & $(0.0205)$ & & & & & & & & \\
\hline Family size $=2$ & -0.0013 & $(0.0082)$ & 0.0023 & $(0.0126)$ & $0.0331 * * *$ & $(0.0113)$ & $0.0310^{* * *}$ & $(0.0106)$ & & & & \\
\hline Family size $>2$ & -0.0091 & $(0.0100)$ & -0.0087 & $(0.0100)$ & $-0.0233^{* *}$ & $(0.0134)$ & $-0.0232 *$ & $(0.0136)$ & $0.0259 * * *$ & $(0.0071)$ & $0.0254 * * *$ & $(0.0078)$ \\
\hline \multicolumn{13}{|c|}{ By birth order and gender composition of elder sibling(s) } \\
\hline One boy & & & & & -0.0105 & $(0.0086)$ & -0.0103 & $(0.0085)$ & & & & \\
\hline One girl & & & & & $0.0277 * *$ & $(0.0118)$ & $0.0279 * * *$ & $(0.0086)$ & & & & \\
\hline Two boys & & & & & & & & & -0.0264 & $(0.0245)$ & -0.0177 & $(0.0241)$ \\
\hline One girl, one boy & & & & & & & & & 0.0141 & $(0.0130)$ & 0.0144 & $(0.0126)$ \\
\hline Two girls & & & & & & & & & $0.0376 * *$ & $(0.0179)$ & $0.0335^{*}$ & $(0.0182)$ \\
\hline
\end{tabular}

Note: Standard errors are in parentheses; * significant at $10 \%$; ** significant at $5 \% ; * * *$ significant at $1 \%$. The dependent variable is a dummy indicating the gender of the child; it equals 1 if the child is a boy, otherwise 0 . The data set used is Sample 2 with a total of 1,880,322 observations (see Table 1). DD (1) refers to the DD estimates without control variables, and DD (2) refers to DD estimates controlling for rural, province, and mother and father's education level dummies. 
Table 4: Difference-in-Differences estimates of the effect of the one-child policy on the probability of being a boy by registration type

\begin{tabular}{|c|c|c|c|c|c|c|c|c|}
\hline \multirow{3}{*}{$\begin{array}{l}\text { Birth cohort } \\
\text { Post-policy change } \\
\text { period }\end{array}$} & \multicolumn{8}{|c|}{ Dependent variable: Gender } \\
\hline & \multicolumn{4}{|c|}{ Rural } & \multicolumn{4}{|c|}{ Urban } \\
\hline & \multicolumn{2}{|c|}{$\begin{array}{l}\text { DD estimates } \\
\text { (1) } \\
\end{array}$} & \multicolumn{2}{|c|}{$\begin{array}{c}\text { DD estimates } \\
\text { (control provincial indicators) } \\
(2) \\
\end{array}$} & \multicolumn{2}{|c|}{$\begin{array}{c}\text { DD estimates } \\
\text { (3) } \\
\end{array}$} & \multicolumn{2}{|c|}{$\begin{array}{c}\text { DD estimates } \\
\text { (control provincial indicators) } \\
(4)\end{array}$} \\
\hline 1980 & $0.0084^{*}$ & $(0.0044)$ & $0.0085 *$ & $(0.0043)$ & 0.0025 & $(0.0154)$ & 0.0017 & $(0.0153)$ \\
\hline 1981 & $0.0170 * * *$ & $(0.0038)$ & $0.0167 * * *$ & $(0.0038)$ & 0.0132 & $(0.0128)$ & 0.0123 & $(0.0125)$ \\
\hline 1982 & 0.0053 & $(0.0070)$ & 0.0049 & $(0.0070)$ & $0.0293 * * *$ & $(0.0108)$ & $0.0286 * * *$ & $(0.0106)$ \\
\hline 1983 & $0.0163 * * *$ & $(0.0049)$ & $0.0158 * * *$ & $(0.0049)$ & -0.0047 & $(0.0104)$ & 0.0053 & $(0.0103)$ \\
\hline 1984 & $0.0144 * * *$ & $(0.0043)$ & $0.0142 * * *$ & $(0.0043)$ & 0.0035 & $(0.0128)$ & 0.0026 & $(0.0133)$ \\
\hline 1985 & $0.0130 * * *$ & $(0.0035)$ & $0.0130 * * *$ & $(0.0034)$ & -0.0168 & $(0.0118)$ & -0.0183 & $(0.0118)$ \\
\hline 1986 & $0.0068 *$ & $(0.0040)$ & 0.0064 & $(0.0041)$ & -0.0065 & $(0.0124)$ & -0.0074 & $(0.0122)$ \\
\hline 1987 & $0.0145^{* *}$ & $(0.0063)$ & $0.0140 * *$ & $(0.0064)$ & -0.0001 & $(0.0112)$ & -0.0013 & $(0.0110)$ \\
\hline 1988 & $0.0108 * *$ & $(0.0052)$ & $0.0101^{*}$ & $(0.0052)$ & -0.0099 & (00110) & -0.0116 & $(0.0108)$ \\
\hline 1989 & $0.0169 * * *$ & $(0.0042)$ & $0.0161^{* * *}$ & $(0.0044)$ & -0.0041 & (0.0103) & -0.0058 & $(0.0098)$ \\
\hline 1990 & $0.0164 * *$ & $(0.0070)$ & $0.0153^{* *}$ & (0.0073) & 0.0077 & (0.0139) & 0.0073 & $(0.0136)$ \\
\hline $1980-1990$ & $0.0126 * * *$ & $(0.0028)$ & $0.0122 * * *$ & $(0.0027)$ & 0.0008 & $(0.0069)$ & 0.0003 & $(0.0067)$ \\
\hline Provincial dummies & & Jo & & & & & $\mathrm{Y}$ & \\
\hline $\mathrm{N}$ & & & 2,991 & & & & 498 & \\
\hline
\end{tabular}

Note: Standard errors are in parentheses; * significant at $10 \%$; ** significant at $5 \%$; *** significant at $1 \%$. The dependent variable is a dummy indicating the gender of the child; it equals 1 if the child is a boy, otherwise 0. The data set used is Sample 1 with a total of 3,856,489 observations (see Table 1). Columns (2) and (4) report the DD estimates with the control vector of provincial dummies for rural and urban subsamples, respectively. 
Table 5: Difference-in-Differences estimates of the effect of the one-child policy on other outcome variables

\begin{tabular}{|c|c|c|c|c|}
\hline \multirow[b]{2}{*}{ Dependent variables } & \multicolumn{2}{|c|}{ Total population } & \multicolumn{2}{|c|}{ Rural residents } \\
\hline & \multicolumn{2}{|c|}{$\mathrm{DD}$} & \multicolumn{2}{|c|}{ DD } \\
\hline \multicolumn{5}{|l|}{ Family structure } \\
\hline \# Aged 64+ in the household & -0.0066 & $(0.0059)$ & -0.0082 & $(0.0065)$ \\
\hline Father is the household head & 0.0018 & $(0.0026)$ & 0.0010 & $(0.0017)$ \\
\hline \multicolumn{5}{|l|}{ Age at the first birth } \\
\hline Mother's age at the first birth & 0.0084 & $(0.0898)$ & -0.0259 & $(0.0876)$ \\
\hline \multicolumn{5}{|l|}{ Father } \\
\hline Education level & 0.0580 & $(0.0360)$ & 0.0519 & $(0.0343)$ \\
\hline Senior School & 0.0146 & $(0.0158)$ & 0.0090 & $(0.0146)$ \\
\hline College and higher & -0.0007 & $(0.0028)$ & -0.0017 & $(0.0013)$ \\
\hline Working & $-0.0013^{*}$ & $(0.0007)$ & -0.0009 & $(0.0006)$ \\
\hline On-farm working & & & -0.0072 & $(0.0052)$ \\
\hline Off-farm working & & & 0.0065 & $(0.0052)$ \\
\hline Unable to work & 0.0006 & $(0.0004)$ & 0.0004 & $(0.0002)$ \\
\hline \multicolumn{5}{|l|}{ Mother } \\
\hline Education level & $0.1004^{* *}$ & $(0.0450)$ & $0.1030^{* *}$ & $(0.0412)$ \\
\hline Senior School & 0.0141 & $(0.0131)$ & 0.0085 & $(0.0088)$ \\
\hline College and higher & -0.0017 & $(0.0026)$ & 0.0001 & $(0.0003)$ \\
\hline Working & -0.0082 & $(0.0058)$ & -0.0074 & $(0.0046)$ \\
\hline On-farm working & & & -0.0048 & $(0.0048)$ \\
\hline Off-farm working & & & -0.0026 & $(0.0024)$ \\
\hline Unable to work & -0.0001 & $(0.0001)$ & -0.0001 & $(0.0001)$ \\
\hline $\mathrm{N}$ & \multicolumn{2}{|c|}{$1,880,322$} & \multicolumn{2}{|c|}{$1,621,821$} \\
\hline
\end{tabular}

Note: Standard errors are in parentheses; * significant at $10 \%$; ** significant at $5 \%$; *** significant at $1 \%$; provincial indicators are controlled for in all regressions. The data set used is Sample 2 (see Table 1). 
Table 6: Difference-in-Differences estimates of the effect of the one-child policy on the probability of being a boy: Provinces versus autonomous regions

Dependent variable: Gender

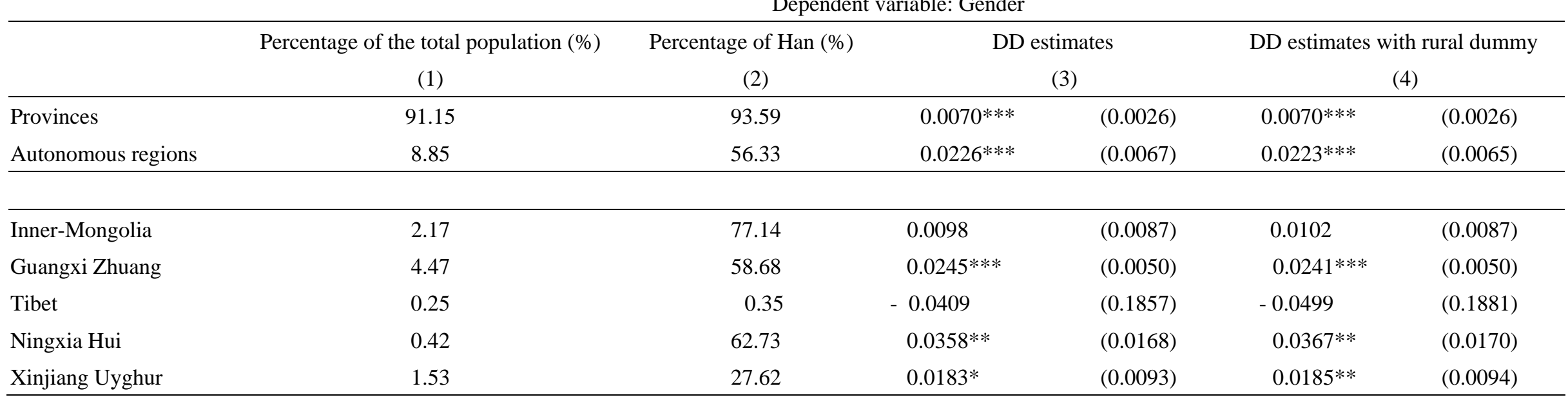

Note: Standard errors are in parentheses; * significant at 10\%; ** significant at 5\%; *** significant at $1 \%$. The dependent variable is a dummy indicating the gender of the child; it equals 1 if the child is a boy, otherwise 0 . The data set used is Sample 1 with a total of 3,856,489 observations (see Table 1). The first panel reports the DD estimates for provinces and autonomous regions, respectively, and the second panel reports the DD estimates for each of the five autonomous regions, respectively. 
Table 7: Difference-in-Differences estimates of the effect of the one-child policy on the probability of being a boy by using the 2000 census and 2005 mini-census

\begin{tabular}{|c|c|c|c|c|c|c|}
\hline & \multicolumn{6}{|c|}{ Dependent variable: Gender } \\
\hline & \multicolumn{3}{|c|}{2000 census } & \multicolumn{3}{|c|}{2005 mini-census } \\
\hline & (1) & (2) & (3) & (4) & (5) & (6) \\
\hline Han & $\begin{array}{l}0.0004 \\
(0.0014)\end{array}$ & $\begin{array}{l}-0.0004 \\
(0.0015)\end{array}$ & $\begin{array}{l}-0.0001 \\
(0.0015)\end{array}$ & $\begin{array}{l}0.0004 \\
(0.0014)\end{array}$ & $\begin{array}{l}0.0004 \\
(0.0016)\end{array}$ & $\begin{array}{l}0.0002 \\
(0.0016)\end{array}$ \\
\hline Treat & $\begin{array}{l}0.0119 * * * \\
(0.0018)\end{array}$ & $\begin{array}{l}0.0134 * * * \\
(0.0018)\end{array}$ & $\begin{array}{l}0.0137 * * * \\
(0.0018)\end{array}$ & $\begin{array}{l}0.0131 * * \\
(0.0037)\end{array}$ & $\begin{array}{l}0.0134 * \\
(0.0038)\end{array}$ & $\begin{array}{l}0.0138 * \\
(0.0038)\end{array}$ \\
\hline DD & $\begin{array}{l}0.0152 * * * \\
(0.0019)\end{array}$ & $\begin{array}{l}0.0135 * * * \\
(0.0019)\end{array}$ & $\begin{array}{l}0.0137 * * * \\
(0.0019)\end{array}$ & $\begin{array}{l}0.0158 * * * \\
(0.0040)\end{array}$ & $\begin{array}{l}0.0143 * * * \\
(0.0041)\end{array}$ & $\begin{array}{l}0.0140 * * * \\
(0.0041)\end{array}$ \\
\hline Constant & $\begin{array}{l}0.5149 * * * \\
(0.0013)\end{array}$ & $\begin{array}{l}0.5169 * * * \\
(0.0040)\end{array}$ & $\begin{array}{l}0.5137 * * * \\
(0.0040)\end{array}$ & $\begin{array}{l}0.5149 * * * \\
(0.0013)\end{array}$ & $\begin{array}{l}0.5214 * * * \\
(0.0052)\end{array}$ & $\begin{array}{l}0.5234 * * * \\
(0.0052)\end{array}$ \\
\hline Rural indictor & No & No & Yes & No & No & Yes \\
\hline Province indicators & No & Yes & Yes & No & Yes & Yes \\
\hline $\mathrm{N}$ & 3033321 & 3033321 & 3033321 & 1656094 & 1656094 & 1656094 \\
\hline
\end{tabular}

Note: Standard errors are in parentheses; * significant at $10 \%$; ** significant at $5 \%$; *** significant at $1 \%$. The dependent variable is a dummy indicating the gender of the child; it equals 1 if the child is a boy, otherwise 0 . 
Table 8: The effects of the one-child policy on the sex ratio across the 1990 census, 2000 census, and the 2005 mini-census

\begin{tabular}{lllll}
\hline \hline & $\begin{array}{l}\text { Actual sex } \\
\text { ratio } \\
(1)\end{array}$ & $\begin{array}{l}\text { Total increase in } \\
\text { sex ratio } \\
(2)\end{array}$ & $\begin{array}{l}\text { One-child } \\
\text { policy effect } \\
(3)\end{array}$ & $\begin{array}{l}\text { Percentage explained } \\
\text { by the one-child policy } \\
\text { (4) }\end{array}$ \\
\hline & & & & \\
$1973-1979$ (1990 census) & 106.31 & & 4.40 & $93.62 \%$ \\
$1980-1990$ (1990 census) & 111.01 & 4.70 & 6.98 & $57.12 \%$ \\
$1991-2000$ (2000 census) & 118.53 & 12.22 & 7.01 & $53.59 \%$ \\
$2001-2005$ (2005 mini-census) & 119.39 & 13.08 & & \\
\hline
\end{tabular}

Note: Column (1) reports actual sex ratios at different periods; column (2) calculates the total increases in sex

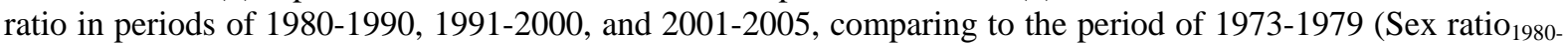
1990 - Sex ratio $1973-1979$, Sex ratio $1990-2000$ - Sex ratio ${ }_{1973-1979}$, Sex ratio $2001-2005$ - Sex ratio $1973-1979$ ); column (3) calculates the effect of the one-child policy on sex ratio by using Equation (3); column (4) calculates the percentage of the total increase in sex ratio accounted for by the one-child policy (column (3)/column (2)). 